\title{
Semantic and Syntactic Interference in Sentence Comprehension: A Comparison of Working Memory Models
}

\author{
Yingying Tan ${ }^{1+}$, Randi C. Martin ${ }^{1 *}$ and Julie A. Van Dyke ${ }^{2}$ \\ ${ }^{1}$ Department of Psychology, Rice University, Houston, TX, USA, ${ }^{2}$ Haskins Laboratories, New Haven, CT, USA
}

OPEN ACCESS

Edited by:

Ping Li,

Pennsylvania State University, USA

Reviewed by:

Andrea Eyleen Martin-Nieuwland,

University of Edinburgh, UK

Chun-Ting Hsu,

Pennsylvania State University, USA

*Correspondence:

Randi Martin

rmartin@rice.edu

${ }^{\dagger}$ Present Address:

Yingying Tan,

Max Planck Institute for

Psycholinguistics, Nijmegen,

Netherlands

Specialty section:

This article was submitted to

Language Sciences,

a section of the journal

Frontiers in Psychology

Received: 04 November 2016 Accepted: 31 January 2017

Published: 15 February 2017

Citation:

Tan Y, Martin RC and Van Dyke JA (2017) Semantic and Syntactic Interference in Sentence Comprehension: A Comparison of Working Memory Models.

Front. Psychol. 8:198.

doi: 10.3389/fpsyg.2017.00198
This study investigated the nature of the underlying working memory system supporting sentence processing through examining individual differences in sensitivity to retrieval interference effects during sentence comprehension. Interference effects occur when readers incorrectly retrieve sentence constituents which are similar to those required during integrative processes. We examined interference arising from a partial match between distracting constituents and syntactic and semantic cues, and related these interference effects to performance on working memory, short-term memory (STM), vocabulary, and executive function tasks. For online sentence comprehension, as measured by self-paced reading, the magnitude of individuals' syntactic interference effects was predicted by general WM capacity and the relation remained significant when partialling out vocabulary, indicating that the effects were not due to verbal knowledge. For offline sentence comprehension, as measured by responses to comprehension questions, both general WM capacity and vocabulary knowledge interacted with semantic interference for comprehension accuracy, suggesting that both general WM capacity and the quality of semantic representations played a role in determining how well interference was resolved offline. For comprehension question reaction times, a measure of semantic STM capacity interacted with semantic but not syntactic interference. However, a measure of phonological capacity (digit span) and a general measure of resistance to response interference (Stroop effect) did not predict individuals' interference resolution abilities in either online or offline sentence comprehension. The results are discussed in relation to the multiple capacities account of working memory (e.g., Martin and Romani, 1994; Martin and He, 2004), and the cue-based retrieval parsing approach (e.g., Lewis et al., 2006; Van Dyke et al., 2014). While neither approach was fully supported, a possible means of reconciling the two approaches and directions for future research are proposed.

Keywords: retrieval interference, working memory capacity, cue-based retrieval, sentence comprehension

\section{INTRODUCTION}

Understanding spoken or written language in real time is essential to our daily life. The ubiquitous presence of long distance linguistic dependencies (e.g., subject-verb dependencies across a relative clause as, for example, in "The director who embarrassed the actor apologized") indicates that some type of memory representation is needed for successful integration of the dependent items. 
Although, there has been a long history of investigation into the role of working memory (WM) in sentence comprehension, controversy remains regarding the kind of memory system that is critical for online sentence parsing.

Most studies of the role of WM in sentence processing have focused on capacity demands involved in maintaining constituents prior to integration or maintaining predictions of upcoming syntactic structure (Daneman and Carpenter, 1980; King and Just, 1991; Just and Carpenter, 1992; Gibson, 1998, 2000; Gordon et al., 2001, 2002, 2004; Warren and Gibson, 2002; Fedorenko et al., 2006, 2007; Daneman and Hannon, 2007). For example, capacity-based accounts attribute the standard advantage in speed and accuracy for processing subject relative clauses (SRCs, as in 1a) compared to object relative clauses (ORCs, as in $1 \mathrm{~b}$ ) to increased WM demands imposed by ORC constructions (Gibson, 1998, 2000; Warren and Gibson, 2002).

(1a) SRC: The reporter who attacked the senator admitted the error.

(1b) ORC: The reporter who the senator attacked admitted the error.

Sentences like (1a) could be interpreted in a largely incremental fashion. The attachment of the gap in subject position of the $\mathrm{RC}$ to "reporter" happens immediately as the verb "attacked" is parsed. However, according to the WM capacity account, comprehenders have to hold "reporter" in sentence (1b) across some new discourse referents (e.g., the object referent "senator") before attaching it to "attacked" as an object. Thus, the activation of "reporter" decays more in the ORC structure due to more discourse referents being processed and fewer resources being available for maintaining syntactic representations, as there is assumed to be a trade-off between processing and maintenance in most capacity models.

A more recent body of work has focused on interference as an explanation for these effects. These studies emphasize the content of memory representations, rather than the quantity of information that can be actively maintained in memory (Gordon et al., 2001, 2004, 2006; Van Dyke and Lewis, 2003; Lewis et al., 2006; Van Dyke and McElree, 2006, 2011; Van Dyke, 2007). For instance, Gordon et al. $(2001,2004)$ demonstrated that the standard disadvantage for ORCs compared to SRCs was substantially reduced when the two noun phrases (NPs) prior to the verb had dissimilar referential properties - that is, when the embedded clause NP (e.g., "the senator" in 1a and 1b) was replaced by a pronoun (e.g., "you") or proper name (e.g., "Joe"). They concluded that their results favored a similarity-based interference account in which memory retrieval was hampered by similarity in the referential properties of the constituent NPs. These findings were not compatible with a pure memory capacity-based account, since the WM loads were the same across noun distinctiveness conditions. Importantly, however, Van Dyke and Lewis (2003) and Van Dyke (2007) have demonstrated that the same nouns may cause more or less interference in sentence comprehension depending on their syntactic roles in the sentence. For example, for sentences ( $2 \mathrm{a}$ and $2 \mathrm{~b}$ ) below, longer processing times at the main verb "was complaining" and greater comprehension errors were observed for sentences like (2b), where the noun phrase (i.e., "warehouse") was a syntactic subject than when it was the object of a prepositional phrase (as in 2a), although the distances between "was complaining" and its subject "resident" were the same.

(2a) The worker was surprised that the resident who was living near the dangerous warehouse was complaining about the investigation.

(2b) The worker was surprised that the resident who said that the warehouse was dangerous was complaining about the investigation.

Van Dyke and colleagues (Van Dyke and Lewis, 2003; Van Dyke, 2007) attributed this effect to the fact that comprehenders need to retrieve the main clause subject in order to integrate it with the main verb ("was complaining"). The fact that "warehouse" is a syntactic subject in (2b) causes more interference in locating the appropriate subject ("worker") than when "warehouse" is a prepositional object as in (2a). Relatedly, greater difficulty is observed when the intervening noun phrase has semantic properties that make it more plausible as the subject of the main clause verb. For example, longer reading times and more errors to comprehension questions are observed for sentences like (2c) than (2b), due to "neighbor" being a more plausible subject of "was complaining" than "warehouse." Thus, these studies demonstrated both syntactic and semantic interference effects during sentence processing.

(2c) The worker was surprised that the resident who said that the neighbor was dangerous was complaining about the investigation.

To explain these and other interference effects, Lewis et al. have advocated a cue-based parsing approach to sentence comprehension (McElree, 2000; McElree et al., 2003; Van Dyke and Lewis, 2003; Lewis et al., 2006; Van Dyke and McElree, 2006, 2011; Van Dyke, 2007). According to this approach, sentence parsing is accomplished through a series of efficient cue-based memory retrievals. The retrieval cues are a subset of the features of the item to be retrieved, and they are derived from the incoming word, context, and grammatical knowledge. Using evidence from both empirical studies and computational modeling, these researchers have suggested that sentence processing is constrained by the degree of interference from non-target constituents, instead of storage demands. Importantly, Lewis and colleagues found that the degree of interference as predicted by the cue-based parsing theory could successfully account for effects observed in previous studies that had been attributed to storage demands, such as longer reading times (RTs) in ORC vs. SRC structures (Van Dyke and Lewis, 2003; Lewis and Vasishth, 2005; Lewis et al., 2006). In addition to the assumption of an extra retrieval in linking the object gap to the relative pronoun in ORCs, this approach suggests difficulty for ORCs due to interference from "reporter" while binding "senator" as the subject of the embedded verb in sentence 1. That is, in the ORC, when processing "attacked," comprehenders need to retrieve a syntactic subject that is semantically plausible as its agent (Van Dyke, 2007). "Reporter" fits both of these 
requirements. In contrast, in the SRC, there is no other preceding noun phrase to provide interference.

\section{INDIVIDUAL DIFFERENCES IN WM AND THEIR ROLE IN SENTENCE PROCESSING}

As the cue-based retrieval approach focuses on interference as the source of difficulty in sentence processing, there is less need to resort to memory capacity as an explanatory factor per se. The move away from capacity accounts is consistent with recent embedded processes accounts of WM, which define WM as the activated portion of long-term memory, together with a very small number of these activated items (e.g., from one to four) within the focus of attention (Lewis, 1996; Cowan, 1999, 2000; Oberauer, 2002; McElree, 2006; Öztekin et al., 2010). In the embedded processes view, information outside the focus is accessed via cue-based retrieval. Consonant with this WM approach, the cue-based parsing model of sentence processing assumes that skilled sentence processing depends on the maintenance of as few as 1-2 chunks of information in WM. Information outside the focus is retrieved through a match of retrieval cues to stored representations. These hypotheses have been supported through a computational implementation (Lewis and Vasishth, 2005; Lewis et al., 2006), and behavioral studies, using a range of methodologies, including self-paced reading, eye-tracking, and speed-accuracy tradeoff techniques (McElree and Dosher, 1989; McElree, 2000, 2006; Van Dyke and Lewis, 2003; Van Dyke and McElree, 2006, 2011; Van Dyke, 2007; Van Dyke and Johns, 2012). The claims from the cuebased parsing approach challenge research pointing to individual differences in WM capacity as a source of sentence processing difficulty (Daneman and Carpenter, 1980; Fedorenko et al., 2006, 2007; Daneman and Hannon, 2007; Unsworth and Engle, 2007). If skilled sentence processing requires at most 1-2 chunks of active memory, this renders moot the claim that poor sentence comprehension is due to low WM capacity.

However, despite the substantial evidence in favor of such a highly limited WM capacity, some criticisms have been raised (Cowan, 2011; Caplan and Waters, 2013). Even among memory researchers who endorse an embedded processes account of $\mathrm{WM}$, there is an ongoing debate about the storage limits of the focus of attention. For example, while McElree and colleagues (e.g., McElree and Dosher, 1989; Öztekin et al., 2010) have estimated the capacity of the focus of attention to be only one chunk of information based on behavioral and neuroimaging results, Cowan (2011) has critiqued these claims and argued for a multi-item focus of attention with a limit of about 3 or 4 chunks. With a larger capacity for the focus of attention, the possibility remains of meaningful individual differences in this capacity. In fact, Unsworth et al. (2014) and Shipstead et al. (2014) have argued, based on a confirmatory factor analytic approach, that a contributing factor to variation in working memory capacity is the capacity of the focus of attention. Therefore, it remains important to examine whether measures of working memory capacity predict comprehension performance, once other relevant factors have been controlled for.
Historically, a substantial body of research has shown a relation between WM capacity measures and the ability to process complex sentences (Daneman and Carpenter, 1980; King and Just, 1991; Just and Carpenter, 1992; Gibson, 1998; Fedorenko et al., 2006, 2007; Daneman and Hannon, 2007; see Long et al., 2006, for a review). Most commonly, these studies have used complex span measures, such as reading span and operation span to index WM capacity (Daneman and Carpenter, 1980; Turner and Engle, 1989). These measures involve both processing and storage components, in that individuals carry out some processing task (e.g., sentence verification in the reading span task or arithmetic computations in the operation span task) while simultaneously maintaining a secondary verbal load (e.g., words or letters). The claim has thus been that these measures reflect a single capacity that can be flexibly allocated to either processing or storage (Just and Carpenter, 1992). In the sentence comprehension domain, storage could involve maintenance of, for instance, lexical items or conceptual representations, and processing could involve, for instance, accessing these representations or assigning thematic roles.

The importance of using WM measures that combine both processing and storage has been emphasized, as other indices of WM capacity such as standard digit or word span, which mainly reflect storage of phonological representations (Baddeley et al., 1998) have typically shown little relation with the ability to process syntactically complex sentences (Waters et al., 1991; Martin and Romani, 1994; Daneman and Merikle, 1996; Caplan and Waters, 1999; Hanten and Martin, 2000; Friedmann and Gvion, 2003; Daneman and Hannon, 2007; Caplan et al., 2013; Kush et al., 2015). Some recent studies, however, have provided some support for a role for phonological storage in complex sentence comprehension (Acheson and MacDonald, 2011; Pettigrew and Hillis, 2014), suggesting that the issue may warrant further attention.

Even though complex span measures have more consistently shown a relation to sentence processing, the source of the WMlanguage relationship remains unclear, as WM capacity might relate to various aspects of comprehension. For example, Caplan and Waters (1999) showed that many of the findings relating complex span measures to online comprehension ability failed to replicate or did not support the conclusions that had been drawn. In their own work, they found that neither simple span (e.g., digit span) nor complex span measures related to online measures of syntactic processing ability - that is, measures related to the processing of each word as the sentence unfolds. However, these measures did relate to offline processing ability, which involves using the products of comprehension to carry out some task such as matching a sentence to a picture. The implication is that the WM tapped by span tasks is involved in reviewing or checking the results of comprehension rather than the initial interpretation of a sentence. Thus, Caplan and Waters (1999) concluded that for online sentence processing, a WM system specialized for language interpretation is involved. More recent work by Caplan and colleagues (Caplan et al., 2013; Evans et al., 2015) has supported these conclusions.

In contrast to the inconsistent results for complex span measures and simple span measures tapping phonological 
storage, one measure which has been consistently related to argument integration during sentence processing is the category probe task, an index of semantic short-term memory (STM) in which participants are presented with a word list and asked to judge whether a probe word is in the same semantic category as any list word (Martin and Romani, 1994; Martin et al., 1994; Hanten and Martin, 2000; Martin and He, 2004; Martin, 2005; Harris et al., 2013). Martin et al. (1994); Martin and He (2004) reported a double dissociation between aphasic patients with semantic STM deficits and patients with phonological STM deficits, with the two types of STM deficits having different consequences for sentence comprehension. Aphasic patients with impaired semantic STM but relatively spared phonological retention had difficulty in understanding sentences in which the integration of semantic information of words was delayed rather than immediate. For example, when detecting the anomaly in sentences in which one to three nouns appeared before a verb (e.g., "Rugs cracked during the move"; "Rugs, vases, and mirrors cracked during the move") relative to sentences in which the nouns followed the verb (e.g., "The movers cracked the rugs"; "The movers cracked the mirrors, vases, and rugs"), performance was equivalent and at a high level when there was only one noun preceding or following the verb, but declined substantially with increasing numbers of nouns before the verb, but remained at the same high level with increasing numbers of nouns after the verb. Similar results were obtained for sentences with varying numbers of adjectives before a noun ("The rusty old red swimsuit"...) vs. after a noun (e.g., "The swimsuit was old, red, and rusty...). In contrast, patients with a phonological STM deficit showed a normal pattern of effects of the delayed vs. immediate integration conditions but had difficulty with sentence repetition (Hanten and Martin, 2000; Martin and He, 2004). Interestingly, the patients with semantic STM deficits performed at a high level and showed no effect of distance on a grammaticality judgment task that varied the distance between words signaling a grammatical error in ten different types of sentence structures (e.g., for verb phrase deletion: “The hopeful young contestants didn't win and neither *was their rather aggressive competitor" vs. "Susan didn't leave despite many hints from her tired hosts and neither *was Mary"). In contrast, one patient who had little deficit in either semantic or phonological STM demonstrated a detrimental effect of distance in this grammaticality judgment task (Martin and Romani, 1994; Martin and He, 2004). Thus, Martin and colleagues put forward a multiple-component model within the language processing domain, with separate capacities for the retention of phonological, semantic, and syntactic information (Martin and Romani, 1994; Martin and Saffran, 1997; Martin and Freedman, 2001; Martin et al., 2003; Martin and He, 2004; Hamilton et al., 2009). According to this model, semantic and syntactic STM capacities, but not phonological STM, are critical for maintaining unintegrated word meanings and syntactic structures during sentence comprehension, respectively.

However, as discussed earlier, the cue-based parsing approach challenges the long-standing assumption that individual differences in WM capacity are a source of the variation in sentence processing ability, and provides an alternative explanation of the prior neuropsychological results. According to the cue-based parsing approach, comprehension difficulty may arise either from variation in the quality of to-be-retrieved representations, or variation in the ability to efficiently use retrieval cues to activate target information and inhibit irrelevant information (Van Dyke et al., 2014). These two accounts point to language experience and executive control ability as playing important roles for determining comprehension ability. Thus, the relation between semantic STM and sentence comprehension might actually reflect underlying deficits in semantic knowledge representations, which resulted in less rich encoding of semantic features during sentence processing. This assumption is partially supported by the finding that even though the patients with semantic STM deficits in Martin et al.'s studies performed well in terms of accuracy on single word semantic tasks, they did show some deficits in latencies on certain timed semantic tasks (Martin and Romani, 1994; Martin and He, 2004). Thus, these patients may have had some mild degree of semantic deficit per se that affected their comprehension. Another possibility is that these patients have a deficit in the mechanism employed for interference resolution. There are findings suggesting that the left inferior frontal region damaged in the patients with semantic STM deficits is crucial for aspects of executive function (Hamilton and Martin, 2005, 2007), i.e., "semantic control" according to Lambon Ralph and colleagues (Jefferies et al., 2007; Whitney et al., 2011) and "selection from competitors" according to Thompson-Schill and colleagues (Novick et al., 2009; Barde et al., 2010), both of which might be involved in interference resolution during sentence comprehension. Thus, to evaluate the multiple capacities hypothesis, it would be important to show that semantic capacity predicts semantic interference resolution, even after taking into account variations in semantic knowledge and executive control.

Thus, far there has been only a single study to investigate individual differences in sensitivity to interference during sentence processing which takes into account variation in language knowledge. Van Dyke et al. (2014) utilized a dualtask paradigm to assess participants' ability to suppress proactive interference from distractors that appeared in a 3-word memory list (e.g., TABLE, SINK, TRUCK) prior to reading the critical sentence. The critical contrast was between the sentences where the verb was manipulated as follows: It was boat that the guy who drank coffee FIXED/SAILED for 2 sunny days. A previous study (Van Dyke and McElree, 2006) with universitylevel participants demonstrated that when the verb appeared as fixed, participants experienced retrieval interference from the items in the memory list (which are all fixable items). The Van Dyke et al. (2014) study sampled from a broader range of ability levels and administered a comprehensive battery of 24 individual differences measures. After partialling out the variance that each measure shared with a composite measure of IQ (combining the vocabulary and matrix reasoning subtests of the Weschler Abbreviated Scale of Intelligence; Psychological Corp.; Wechsler, 1994/1999), they observed that WM capacity no longer interacted with individuals' sensitivity to interference whereas a receptive vocabulary measure (Peabody Picture Vocabulary Test-Revised; Dunn and Dunn, 1997) did, such that the comprehension for individuals with low vocabulary 
was more affected by interference. Van Dyke et al. interpreted this result as most consistent with the view that the quality of to-be-retrieved representations (assumed to be reflected in the receptive vocabulary measure) is a critical determinant of sensitivity to interference. In addition, Van Dyke et al. also observed a significant interaction of IQ with sensitivity to interference, which mirrored the effect found with vocabulary: individuals with lower IQ were more affected by interference. This interaction with IQ is difficult to fully interpret in light of the findings suggesting that IQ shares significant variance with WMC and that this shared variance is itself multi-faceted (Engle et al., 1999a,b; Kane and Engle, 2002; Hambrick et al., 2005; Kane et al., 2007; Shipstead et al., 2014; Harrison et al., 2015). Due to the collinearity of fluid intelligence and WM, we included the WAIS vocabulary measure (Wechsler, 1997; WAIS-III, 2002) as a control variable, because this task is generally viewed as a measure of crystallized intelligence, which has less shared variance with WM capacity (Kane et al., 2007). The inclusion of this task provides a means of assessing the role of WM capacity independent of lexical processing ability.

For the executive control hypothesis, several prior studies have supported a role for general executive control (e.g., as measured by the verbal Stroop task) in comprehending gardenpath sentences (Novick et al., 2005, 2014; Vuong and Martin, 2014; Hsu and Novick, 2016). Nevertheless, a potential problem with these findings is that the use of garden path constructions, where correct comprehension requires overriding preferred interpretations of words or syntactic structures, may engage resolution processes differently than in unambiguous sentences (i.e., they may be consciously engaged.) Thus, an important contribution of the current study is to provide data on how executive function becomes involved when parsing unambiguous sentences more like those routinely encountered in everyday conversation.

\section{CURRENT STUDY}

The current study is the first to examine individual differences in resolving syntactic and semantic interference from distractors embedded within a sentence during online processing. Motivated by the studies summarized above, we examined whether interference resolution depends on general WM capacity, STM capacity (phonological or semantic), executive control abilities, and/or aspects of representational quality. Given the ongoing debates about the nature of the WM-sentence comprehension relation, we aimed to test specific hypotheses about the relation between these various tasks and language processing as predicted by different theories. We summarize these predictions in Table 1 with reference to the specific tasks we use to represent each cognitive construct (see Section Methods for task descriptions).

While the above accounts entail a range of predictions, some differences between them are critical for the present study. The general WM account implies that WM measures will be related to both semantic and syntactic interference, potentially both in online and offline measures. Thus, numerous interactions between WM and sentence effects are predicted. In contrast, the multiple capacities approach predicts that only specific relations will be obtained-for instance, between a measure of semantic capacity and semantic interference resolution but not syntactic interference resolution. Thus, fewer interactions are predicted which follow specific patterns. The language-specific WM approach predicts no relations between WM measures and sentence processing measures, at least in online processing. The cue-based parsing approach predicts that language knowledge and executive function should interact with interference effects. Interactions with capacity measures are generally not expected. However, based on the findings of Van Dyke et al. (2014) assuming they hold for cases where distractors are embedded within the sentence-interactions with the portion of WM capacity variance related to IQ may occur. This could be predicted for semantic interference, which is the only type of interference examined in the Van Dyke et al. study.

\section{METHODS}

\section{Subjects}

One hundred and twenty undergraduate students (79 females) from Rice University were recruited for this experiment. Each subject participated in two $1.5 \mathrm{~h}$ sessions. All subjects were native English speakers without a diagnosed reading or learning disability and normal or corrected-to-normal vision. Informed consent was obtained from each subject in accordance with the guidelines and approval of the Rice University Institutional Review Board. Subjects received credit toward experiment participation requirements for their courses. Eight subjects were excluded from the analysis due to low accuracy in the sentence comprehension task $(<75 \%)$.

\section{Materials and Procedure Sentence Comprehension Task Materials}

We used modified versions of the sentences in Van Dyke's (2007) study. There were eighty sets of sentences with four different types of sentences in each set crossing two levels of syntactic interference with two levels of semantic interference (see examples in Table 2 or see Appendix A in Supplementary Material for complete list.) To increase readability, we refer to the low and high syntactic interference conditions as LoSyn and HiSyn, respectively, while the low and high semantic interference conditions are referred to as LoSem and HiSem. The four sentences in a set began with the same introduction region and differed in the intervening region, in which semantic and syntactic interference were manipulated. To avoid potential problems associated with local coherence effects (Tabor et al., 2004), an adverbial phrase was inserted after the intervening region in order to increase the separation between the interfering noun and the main clause verb. Difficulty with local coherence might have arisen particularly in the low syntactic interference conditions as the interfering NP would have appeared immediately before the main clause verb without the adverbial phrase. The main verb for the long-distance dependency was identified as the critical region, as this is the point at which comprehenders would attempt to retrieve the 
TABLE 1 | Predictions of the relations between individual differences measurements and interference effects.

\begin{tabular}{|c|c|}
\hline Account & Predictions \\
\hline General WM approach (e.g., Just and Carpenter, 1992; Fedorenko et al., 2006, 2007) & $\begin{array}{l}\text { Complex span measures (e.g., reading span and operation span) should } \\
\text { correlate with the size of both semantic and syntactic interference effects. }\end{array}$ \\
\hline \multirow[t]{3}{*}{ Multiple capacities approach (e.g., Martin et al., 1999; Martin and He, 2004) } & $\begin{array}{l}\text { Semantic STM (e.g. category probe) should correlate with semantic } \\
\text { interference resolution, even after controlling for verbal knowledge and } \\
\text { executive function abilities. }\end{array}$ \\
\hline & $\begin{array}{l}\text { Phonological STM (e.g., digit span) should not correlate with either type of } \\
\text { interference. }\end{array}$ \\
\hline & $\begin{array}{l}\text { Syntactic interference resolution ability should not correlate with either } \\
\text { semantic STM or phonological STM }\end{array}$ \\
\hline Language-specific WM approach (e.g., Caplan and Waters, 1999, 2013) & $\begin{array}{l}\text { There should be no correlations between any WM span tasks and online } \\
\text { interference effects, but only with offline interference effects. }\end{array}$ \\
\hline \multirow[t]{2}{*}{ Cue-based parsing approach (e.g., Van Dyke et al., 2014) } & $\begin{array}{l}\text { Representational quality (e.g., vocabulary) and/or executive function (e.g., } \\
\text { Stroop task) should correlate with the size of interference effects. }\end{array}$ \\
\hline & $\begin{array}{l}\text { Additional interactions between semantic interference and WM measures } \\
\text { may occurb. }\end{array}$ \\
\hline
\end{tabular}

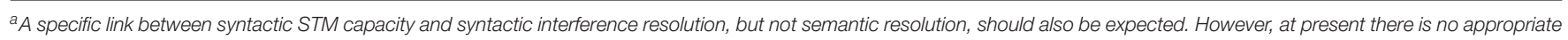
measurement for syntactic STM. Thus, the predictions from the multiple capacities approach focus on the relation between semantic interference and semantic STM capacity.

${ }^{b}$ The results of Van Dyke et al. (2014) suggest that these interactions should stem from variance shared between WM and IQ.

subject NP. The phrase following the main verb is termed the spillover region, because it is often the case that effects in one region spill over to the next region in self-paced reading (Just et al., 1982).

Eighty sets of four sentences were constructed containing the four types of intervening clauses (see Appendix A in Supplementary Material). The mean length of the experimental sentences was 15.7 words ( $\mathrm{SD}=1.3$ words). To avoid repetition of the verbs and sentence content within one subject, the four items in each set were assigned to four lists and each subject received only one list containing one item per set in a list. Two pseudo-randomized sequences were created for each stimulus list, resulting in a total of eight lists. Each subject saw 20 target sentences in each of the four conditions. Additionally, 80 filler items were added to each list consisting of 36 sentences with a relative clause structure (16 with ORC) and 44 non-RC sentences with right-branching structures. The ORC sentences were included in order to distract subjects from detecting the target sentences. In all, each subject saw 160 sentences during the experiment.

\section{Procedure}

Stimuli were presented in a phrase-by-phrase, non-cumulative, self-paced fashion (Just et al., 1982). Ten practice sentences were presented prior to the experimental sentences, consisting of 4 sentences in the same format as experimental sentences and 6 fillers. Participants were instructed to read each sentence for comprehension silently at a natural pace and told that there would be a comprehension question after each sentence. All trials began with a fixation point appearing in the center of the screen for $1,000 \mathrm{~ms}$, followed by the first phrase. Participants pressed a button with their index finger to bring up the phrases in each sentence, and a period was presented together with the last phrase. The reading time (RT) was recorded as the time
TABLE 2 | Example syntactic and semantic interference stimuli for experiment showing phrasal regions for self-paced reading.

\begin{tabular}{|c|c|c|}
\hline Sentence region & & Example stimulus \\
\hline Introduction & & The critic \\
\hline \multirow[t]{4}{*}{ Intervening region } & LoSyn/LoSem & Who had enjoyed the memorable play \\
\hline & LoSyn/HiSem & Who had enjoyed the memorable actress \\
\hline & HiSyn/LoSem & $\begin{array}{l}\text { Who mentioned that the play was } \\
\text { memorable }\end{array}$ \\
\hline & HiSyn/HiSem & $\begin{array}{l}\text { Who mentioned that the actress was } \\
\text { memorable }\end{array}$ \\
\hline Adverbial phrase & & At the new theatre \\
\hline Critical region & & Will visit \\
\hline Spillover region & & The director \\
\hline
\end{tabular}

"LO-" and "Hi-" refer to low and high interference condition, while "-Syn" and "-Sem" refer to syntactic interference and semantic interference condition.

between stimulus onset and button press for each phrase. After each sentence, a comprehension question was presented. For the experimental sentences, the phrase probed the critical subjectverb integration (e.g., for the example sentences, "Who will visit?"). For the filler sentences, the comprehension questions probed other noun phrases in the sentence (e.g., for the filler sentence "The artist who feared that the publicist would cancel the exhibit quit on his own," the comprehension question was "What might be canceled?"). Subjects were required to provide a spoken response, and speed for answering the question was measured through a voice key trigger as the time between question onset and the time when subjects start producing vocal response. The next sentence started after an inter-trial interval of 1,000 ms.

\section{Working Memory Tasks}

To tap subjects' memory capacity, we included two simple span measures and two complex span measures. 


\section{Simple Span Measures Category probe task}

The category probe task (Martin et al., 1994) was included to tap subjects' semantic STM. In this task, subjects were presented with an auditory word list. After a short pause, they heard a probe word and had to judge whether this word was in the same category as any of the words in the list (all of the words in a list were drawn from different categories). Before testing, subjects were shown a list of all nine categories (e.g., animals, clothing, fruits, etc.) that would be presented in the experiment as well as all the words belonging to each category. The number of words in each list ranged from 4 to 7 and there were 24 lists at each list length. The dependent measure was overall accuracy for each subject.

\section{Digit span task}

The digit span task from Wechsler Adult Intelligence Scalethird edition (Wechsler, 1997) was included to tap subjects' phonological STM. Participants heard a list of digits and they were required to repeat the numbers aloud in order at the end of each list. The number of digits in each list ranged from 3 to 9 , and there were 2 trials at each level. Each subject completed all 14 trials. Overall accuracy was calculated for each subject.

\section{Complex Span Measures Operation span task}

The automated version of Operation Span (Unsworth et al., 2005) was used to measure WM capacity. Subjects were instructed to solve a math operation [e.g., $(1 * 2)+1=$ ?] as quickly as possible and then remember a single letter. During this task, a math operation was presented on the screen first. After subjects solved it and clicked the mouse, a digit appeared and subjects judged whether it was the correct answer. After a mouse click response, a letter to be recalled was shown on the screen for 800 ms. This to-be-remembered letter was followed by either another math operation-letter combination or the recall screen, which showed up at the end of each set of operation-letter pairs. At recall, subjects clicked a box next to the appropriate letters in the current set in the order presented. The experimental trials contain three trials at each set size, with set sizes ranging from 3 to 7 items, resulting in a total of 75 trials. The order of set sizes was random for each participant. We evaluated subjects' operation span by the total number of letters recalled in the correct serial position regardless of whether the entire trial was recalled correctly.

\section{Reading span task}

We used the automated version of reading span (Unsworth et al., 2005) modified from Daneman and Carpenter's (1980) original version. The task is very similar to the operation span task, but instead of solving math operations, subjects are instructed to judge whether a presented sentence makes sense or not (e.g., Andy was stopped by the policeman because he crossed the yellow heaven.). After pushing a button to indicate whether the sentence makes sense, a to-be-remembered letter is shown on the screen for $800 \mathrm{~ms}$, which is followed by either another sentence-letter combination or the final recall screen. Set sizes ranged from 3 to
7 items. At the end of each set of sentences, subjects recalled all the letters in the current set in order by clicking boxes next to letters. This results in a total of 75 trials; the order of set sizes was random for each participant. We evaluated subjects' performance with the same scoring procedure as operation span.

\section{Executive Function Measure}

The standard verbal Stroop task (Stroop, 1935) was adopted in the current experiment to measure subjects' resistance to interference. Subjects were required to name the ink color in all conditions. In the congruent condition, a color word appeared in the congruent color (e.g., the word "blue" in blue ink) while in the incongruent condition, a color word was presented in a different ink color (e.g., the word "blue" in red ink). In the neutral condition, a series of colored asterisks was presented. There were 65 incongruent trials, 77 neutral trials, and 12 congruent trials. Response naming latencies were recorded from the onset of the stimulus through a voice key response. The Stroop interference score for each subject was calculated by subtracting the mean correct RT in the neutral condition from that in the incongruent condition.

\section{Verbal Knowledge Measure}

The vocabulary subtest of the WAIS-III (Wechsler, 1997) was administered as a measure of verbal knowledge. The test requires subjects to provide word definitions (e.g., Tell me what confide means). We began the vocabulary test from the 12 th item in this subtest because the words before the 12th were not discriminating enough for our undergraduate students. Twentytwo words were presented. The test was scored based on the standard scoring criteria in the WAIS-III manual. Each definition received either 0,1 , or 2 points.

\section{General Procedure}

Testing was carried out in two sessions, each lasting $\sim 1.5 \mathrm{~h}$ for a total of $3 \mathrm{~h}$. A button box with millisecond accuracy was used for the computerized tasks and a voice key was attached to the button box to record verbal responses. The sentence reading, category probe, digit span, and Stroop tasks were conducted on a Macintosh with PsyScope (Cohen et al., 1993). The reading span and operation span tasks were run using E-Prime (Schneider et al., 2002). The task administration order was fixed for all participants: sentence comprehension task first, followed by digit span, Stroop, vocabulary, category probe, reading span, and operation span.

\section{Data Analysis}

The sentence comprehension experiment produced four dependent variables: reading times (RT) from self-paced reading in the critical region (main verb) and spillover region (the phrase following the main verb), and speed and accuracy for answering comprehension questions. For all RT analyses (i.e., self-paced reading and question answering speed), only data from accurate trials were included. Outliers were calculated by condition for each subject and reading times $>2.5$ standard deviations away from the mean for each condition were removed from the analyses. The trimming removed $4 \%$ of the data in the critical 
region, $4 \%$ of the data in the spillover region, and $5 \%$ of the data in the question answering times.

Because some researchers have claimed that variations in processing speed account for the correlations between WM capacity and performance on complex cognitive tasks (Fry and Hale, 1996; Salthouse et al., 2003), a logarithmic transformation was performed on the RT data in order to remove the effects of speed on the size of effects (Verhaeghen and De Meersman, 1998). This transformation also yields more normally distributed RTs than raw RTs, and thus the transformed data better meet the assumptions underlying the general linear model (Baayen and Milin, 2010) ${ }^{1}$.

The log-transformed RT and error rate data were modeled in linear mixed-effects models (LMEMs) using R (2.11.1) implemented within the lme4 package, with a logistic linking function for dichotomous variables such as comprehension error rate (Baayen, 2008, 2011; Baayen et al., 2008) following guidelines set out by Baayen (2008). Each of the independent variables was mean-centered prior to analysis. This centering allows us to interpret results by making effects analogous to ANOVA results. The semantic and syntactic interference were coded with the low interference condition as -1 and high interference condition as 1. Thus, negative coefficients for each main effect of log RT or error proportion signify worse performance (i.e., longer RT) in the high interference conditions.

In the mixed-effects models, fixed effects included the main effects and interaction of semantic and syntactic interference manipulations, as well as the main effects of all the individual differences and their interactions with semantic/syntactic interference. In addition to these fixed effects, all the mixedeffects models included maximal random-effects structures to provide the most conservative assessment of the significance of results (Barr et al., 2013). Thus, by-subject adjustments to the intercept as well as by-subject adjustments to the random slope of interaction between semantic $\times$ syntactic interference were included in the models. Similarly, by-item adjustments to the intercept and to the random slope of interaction between semantic $\times$ syntactic interference were included. In addition, word length was included as a control factor in all the models for the critical and spillover regions. There was no convergence problem for any of the models reported in this study. Throughout, we present coefficient estimates, standard errors (SE), and $t$ - or $z$-scores (when the dependent measures is a dichotomous variable, i.e., accuracy) derived from 50,000 Monte Carlo Markov Chain (MCMC) runs. For the RT data, the degrees of freedom are not reported because they can only be approximated in LMEMs, and consequently $p$-values are not reported. The $t$ - or $z$-score based on MCMC sampling and $t$ - or $z$-score based on the upper bound of the degrees of freedom tend

\footnotetext{
${ }^{1}$ We have also conducted the analysis with length residualized reading times (Trueswell et al., 1994). The residual RT was calculated for each participant by subtracting the RT predicted by region length from the actual reading time. In the mixed-effects model analysis, the results from models with residual RTs as dependent variables were very similar to the results from models with logtransformed RTs as dependent variables and region length as fixed effect. Thus, we only reported the results of including word length as fixed effect and logtransformed RT as dependent variables here.
}

to be very close for a relatively large sample (Baayen et al., 2008). Hence, we adopted a standard in which an absolute $t$ - equal to or $>2.0$ was considered to be significant at the $\alpha=0.05$ level. For the mixed logistic regression analysis of errors, degrees of freedom can be calculated and thus, $p$-values are reported in the results for these analyses.

\section{RESULTS}

\section{Relations among Individual Differences Measures}

Range, mean, and standard deviation for each individual differences measure are shown in Table 3. Reliabilities are also reported as the extent of relation between two variables is limited by the reliability of the measures involved (Schmitt, 1996). For most measures, internal reliability was calculated as the split-half correlation adjusted with the Spearman-Brown prophecy formula (Cronbach, 1951). For operation span and reading span, the internal reliability was obtained from previous studies (Redick et al., 2012). Although, most subjects tended to perform well in most tasks, their scores were distributed widely on each scale and the reliability of all these tests was very high.

The correlations among the individual differences measures are shown in Table 4. Reading span and operation span had a moderately high correlation $(r=0.54)$, which is consistent with previous studies (as reported by Redick et al., 2012, mean $r=0.64$ ). The category probe measure had low but significant correlations with reading span, operation span and vocabulary. The correlation between digit span and category probe was very low $(r=0.11)$, substantiating the claim that these measures tap different aspects of STM. Digit span was correlated significantly with reading span and operation span, which is consistent with other evidence showing a phonological component to these WM measures (Kane and Engle, 2003; Camos et al., 2011, 2013). In addition, Stroop correlated with both reading span and operation span, also in line with previous findings (Kane et al., 2001), but did not correlate with digit span or category probe. This pattern may be attributed to the attentional control component (i.e., interference resolution ability in the Stroop task), which is more prominent in complex span measures than in simple span measures (Engle, 2002; Kane and Engle, 2003; Engle and Kane, 2004; Unsworth et al., 2009). Lastly, vocabulary had low to moderate correlations with all of the measures except digit span and Stroop.

\section{Semantic and Syntactic Interference and Their Relation to Individual Differences Measures}

Mean error rates and response times for comprehension questions and mean self-paced reading times for the main verb (i.e., critical region) and the following phrase (i.e., spillover region) are shown in Table 5. Subjects generally performed well on the comprehension questions (overall accuracy $=87 \%$ ). The reliability of each sentence comprehension dependent measure was calculated as a split-half correlation adjusted with the 
TABLE 3 | Descriptive data and reliability estimates for all the individual differences measurements.

\begin{tabular}{|c|c|c|c|c|c|c|c|}
\hline Individual differences measures & Index & Mean & Range & SD & Skew & Kurtosis & Reliability \\
\hline Operation span & Partial score & $63 / 75$ & $36-75$ & 8.5 & -0.97 & 0.86 & $0.84^{a}$ \\
\hline Reading span & Partial score & $62 / 75$ & $26-75$ & 10.4 & -0.85 & 0.40 & $0.86^{a}$ \\
\hline Category probe & Accuracy & 0.81 & $0.64-0.94$ & 0.07 & -0.24 & -0.66 & $0.74^{b}$ \\
\hline Digit span & Accuracy & 0.74 & $0.43-1.00$ & 0.14 & -0.02 & -0.89 & $0.73^{b}$ \\
\hline Stroop ${ }^{c}$ & $\mathrm{RT}(\mathrm{ms})$ & 113 & $13-277$ & 58.9 & 0.66 & -0.10 & $0.89^{b}$ \\
\hline Vocabulary & Score & $36 / 44$ & $19-44$ & 5.5 & -0.91 & 0.46 & $0.82^{b}$ \\
\hline
\end{tabular}

${ }^{a}$ Cronbach's Alpha.

${ }^{b}$ Odd-even split-half reliability.

'Stroop effect is calculated by subtracting participants' mean RT in the neutral conditions from that in the incongruent condition.

TABLE 4 | Full correlation matrix of the correlation tests between individual differences measures.

\begin{tabular}{|c|c|c|c|c|c|c|}
\hline Individual differences Measures & Reading span & Operation span & WM composite & Category probe & Digit span & Stroop \\
\hline \multicolumn{7}{|l|}{ Reading span } \\
\hline Operation span & $0.54^{\star \star}$ & & & & & \\
\hline WM composite & $0.88^{* *}$ & $0.88^{\star *}$ & & & & \\
\hline Category probe & $0.33^{\star \star}$ & $0.20^{*}$ & $0.30^{\star \star}$ & & & \\
\hline Digit span & $0.22^{\star}$ & $0.31^{\star *}$ & $0.31^{\star *}$ & 0.11 & & \\
\hline Stroop & $-0.24^{*}$ & $-0.27^{\star \star}$ & $-0.29^{\star \star}$ & -0.03 & -0.13 & \\
\hline Vocabulary & $0.35^{\star \star}$ & $0.23^{\star}$ & $0.33^{\star \star}$ & $0.21^{*}$ & 0.17 & -0.17 \\
\hline
\end{tabular}

${ }^{*} p<0.05 ;{ }^{* *} p<0.01$

The WM composite variable for WM capacity was calculated by combining z-scores for reading span and operation span.

TABLE 5 | Descriptive data of mean proportion errors and reaction time (ms) in sentence comprehension task and self-paced reading time (ms).

\begin{tabular}{lccccc}
\hline Conditions & \multicolumn{2}{c}{ Comprehension questions } & & \multicolumn{2}{c}{ Self-paced reading $(\mathbf{m s})$} \\
\cline { 2 - 3 } & $\begin{array}{c}\text { Error } \\
\text { proportion }\end{array}$ & Speed $(\mathbf{m s})$ & & $\begin{array}{c}\text { Critical } \\
\text { region }\end{array}$ & $\begin{array}{c}\text { Spillover } \\
\text { region }\end{array}$ \\
\hline LoSyn/LoSem & 0.08 & 1,265 & & 920 & 957 \\
LoSyn/HiSem & 0.13 & 1,385 & & 935 & 992 \\
HiSyn/LoSem & 0.12 & 1,281 & & 913 & 980 \\
HiSyn/HiSem & 0.18 & 1,436 & & 938 & 1,039
\end{tabular}

LoSyn and HiSyn refer to low and high syntactic interference conditions. LoSem and HiSem refer to low and high semantic interference conditions

Spearman-Brown prophecy formula (Cronbach, 1951). The reliability of all the dependent measures was very high $(\geq 0.78$; see Appendix C in Supplementary Material). As expected, subjects showed the lowest error rate (8\%) and shortest question answering time (mean $=1,265 \mathrm{~ms}$ ) in the LoSyn/LoSem interference condition, and the highest error rate (18\%) and longest answering time (mean $=1,436 \mathrm{~ms}$ ) in the HiSyn/HiSem interference condition.

To obtain a more reliable and robust measure for general WM capacity and to avoid the collinearity issue between reading span and operation span, we computed a composite WM measure by averaging $z$-scores for the two complex span measures, resulting in a measure which would increase measurement precision of the overlapping component (Nunnally et al., 1967).
In order to examine the unique contribution of general WM, specific STM, or executive function as measured by each cognitive ability task, all the individual differences measures were included in the mixed-effects models simultaneously. That is, to determine whether span measures contributed to the prediction of performance beyond what could be predicted on the basis of verbal knowledge, the main effect of vocabulary and its interactions with semantic or syntactic interference as fixed effects were included in all the models with other individual difference measures. Because of the potential concern about mild multicollinearity among the individual differences measures, we also report in Appendix B in Supplementary Material the output of mixed-effects models with each individual differences measure alone (with vocabulary as a control variable) ${ }^{2}$. Generally, the single predictor analyses provided convergent results to the multiple predictor analyses. Thus, we will only focus on the results from multiple predictor analyses, which revealed the unique contribution of each predictor when controlling for the others.

For these analyses, we focused on the interaction between semantic/syntactic interference and the individual differences measures. In general, individuals with higher capacities or better interference resolution ability should show less difference between high vs. low interference conditions relative to subjects with lower capacities or poorer interference resolution ability.

\footnotetext{
${ }^{2}$ Given that these analyses were intended to determine if collinearity had hidden the contribution of some of the variables, a liberal criterion for significance was used without correction for multiple comparisons.
} 
These effects should show up as significant interaction terms (i.e., interference manipulation $\times$ individual difference measure) in the mixed effects models.

\section{Self-paced Reading Times Model 1 (online measures)}

Semantic/syntactic interference effects and main effects of each individual differences measure are shown in Table 6, and the interactions between sentence processing and individual differences measures are shown in Table 7. Both semantic interference $(t=2.56)$ and syntactic interference $(t=2.03)$ effects were significant in the spillover region, whereas neither was significant at the critical verb (semantic: $t=1.94$; syntactic: $t=-0.02$ ). The interaction between semantic and syntactic interference was not close to significance in either region. The time course of these effects is different from that observed in Van Dyke (2007), in which the syntactic interference effect was obtained at the critical verb, whereas the semantic interference effect was only observed in the final region (after a spillover region). The discrepancies between the results of the current study and Van Dyke's (2007) study may be explained by methodological differences. For one, the current study utilized a self-paced reading paradigm, while the Van Dyke (2007) study provided eye-tracking data. As effects in self-paced reading often spill over into regions following the critical manipulation (e.g., Just and Carpenter, 1992; Bartek et al., 2011), it is possible that an earlier occurring syntactic interference effect may have only become evident in the spillover region. On the other hand, a much larger sample size was used here, which may have made provided the power to detect semantic effects earlier.

With respect to individual differences effects, while the main effect of syntactic interference was not significant in the critical region, there was a significant interaction between syntactic interference and the composite WM measure in this region $(t=$ -2.09), which also appeared in the spillover region $(t=-2.47$; See Figure 1 for a plotting of interaction effects using methods outlined by Dawson, 2014). These interactions indicate online effects of general WM capacity, where those with lower spans tended to have more difficulty with syntactic interference than those with higher spans, with the difference between the high and low span subjects being greatest in the high syntactic interference condition. On the other hand, the interactions between semantic interference and the individual differences measures failed to reach significance in either region. There was also a significant interaction between syntactic interference and digit span in the spillover region, which went in the direction opposite that predicted, indicating that subjects with higher digit span showed larger syntactic interference effects $(t=2.27)$. However, we suggest that digit span acted like a suppressor variable in the WM-syntactic interference relation, rather than playing a crucial independent role. This conclusion is based on the grounds that when digit span was included as a single predictor in the mixed-effects model analysis (with vocabulary as a control variable; as shown in Appendix B in Supplementary Material), the interaction between digit span and syntactic interference was not significant in either the critical region $(t=0.47)$ or spillover region $\left(t=1.62^{3}\right)$, while the interaction between the WM composite and the syntactic interference effect was marginally significant in both the critical $(t=-1.66)$ and the spillover region $(t=-1.99)$. Therefore, because digit span did not play an independent role and the weight for the composite WM measure became higher when including digit span (i.e., when removing the contribution of phonological retention to the composite WM measure), the influence of digit span fits the definition of a suppressor variable. Last, due to the potential concern that the type of WM task affects the observed relations between WM capacity and other cognitive functions (e.g., Shipstead et al., 2014), we also constructed two other models in which only the reading span or operation span measure was included along with all of the other individual differences measures to investigate whether the specific processing component in each complex span measure (i.e., sentence reading in the reading span task and arithmetic computation in the operation span task) modulated the WM-language relation as reported in some previous studies (Unsworth et al., 2009). The results of these two models were very similar to those from Model 1 in terms of the pattern of main effects and interactions (see Appendices D,E in Supplementary Material for full model output). Although, the relations between reading span and syntactic interference were somewhat stronger than those between operation span and syntactic interference, adding reading span to the model with operation span did not significantly improve the fit (see Appendix F in Supplementary Material). Thus, it appears that the interactions between WM and syntactic interference are due to the overlapping variance between reading span and operation span.

\section{Summary of self-paced reading effects}

The findings were in line with previous studies using a similar paradigm in showing semantic and syntactic interference effects in self-paced reading measures (Van Dyke and Lewis, 2003; Van Dyke, 2007). More critically, the present study provides the first evidence that the size of the syntactic interference effect is related to a measure of general WM capacity, and this relation was observed at both the critical and the spillover regions. However, despite the fact that a marginal main effect of semantic interference was obtained in the critical region and a significant effect in the spillover region, no interaction between semantic interference and any of the individual differences measures was observed. It should be noted that the significant interactions between WM capacity and syntactic interference could not be attributed to either verbal knowledge (as measured by WAIS vocabulary) or general executive control ability (as measured by Stroop) as these WM effects were significant even though vocabulary and Stroop were included in the models. Neither vocabulary nor Stroop showed significant interactions with syntactic interference. One might question whether the absence of interactions with vocabulary or Stroop resulted from the significant correlations of these measures with the two WM measures, and thus inclusion of the WM measures masked their influence. However, as shown in Appendix B in Supplementary

\footnotetext{
${ }^{3}$ According to the Student's t-distribution, when $p=0.10, t_{(120)}=1.658, t_{(\infty)}=$ 1.645. Although, the current mixed-effects model results could only estimate the degrees of freedom, it should be a value between 120 and $\infty$.
} 
TABLE 6 | Results of semantic/syntactic interference effects and main effects of each individual differences (IDs) measure in mixed-effects analyses, in which all individual measures were included.

\begin{tabular}{|c|c|c|c|c|c|c|c|c|c|c|c|c|}
\hline & \multicolumn{6}{|c|}{ Self-paced reading (ms) } & \multicolumn{6}{|c|}{ Comprehension question } \\
\hline & \multicolumn{3}{|c|}{ Critical region (RT) } & \multicolumn{3}{|c|}{ Spillover region (RT) } & \multicolumn{3}{|c|}{ Error proportion } & \multicolumn{3}{|c|}{ Speed (RT) } \\
\hline & Coefficient & SE & $t$-score & Coefficient & SE & $t$-score & Coefficient & SE & $z$-score (p-value) & Coefficient & SE & $t$-score \\
\hline Intercept & 2.82800 & 0.02081 & $135.90^{\star}$ & 2.86200 & 0.01735 & $164.97^{\star}$ & -1.70500 & 0.41310 & $-4.13^{\star}(<0.001)$ & 3.07400 & 0.01656 & $185.65^{\star}$ \\
\hline Length & 0.00720 & 0.00139 & $5.19^{\star}$ & 0.00617 & 0.00081 & $7.64^{*}$ & -0.03351 & 0.01872 & $-1.79(0.074)$ & 0.00130 & 0.00067 & 1.94 \\
\hline Semantic interf & 0.00520 & 0.00268 & 1.94 & 0.00661 & 0.00259 & $2.56^{\star}$ & 0.27850 & 0.04903 & $5.68^{*}(<0.001)$ & 0.01933 & 0.00203 & $9.52^{*}$ \\
\hline Syntactic interf & -0.00006 & 0.00286 & -0.02 & 0.00496 & 0.00245 & $2.03^{*}$ & 0.13100 & 0.04764 & $2.75^{\star}(0.006)$ & 0.00434 & 0.00178 & $2.44^{*}$ \\
\hline Sem $\times$ Syn & 0.00183 & 0.00255 & 0.72 & 0.00119 & 0.00222 & 0.54 & -0.00141 & 0.04641 & $-0.03(0.976)$ & 0.00252 & 0.00179 & 1.41 \\
\hline \multicolumn{13}{|l|}{ IDs } \\
\hline Category probe & 0.61350 & 0.18750 & $3.27^{*}$ & 0.42250 & 0.19410 & $2.18^{*}$ & -2.10900 & 0.83330 & $-2.53^{\star}(0.011)$ & -0.01326 & 0.10660 & -0.12 \\
\hline WM Composite & -0.01053 & 0.00860 & -1.22 & -0.01146 & 0.00890 & -1.29 & -0.06856 & 0.03766 & $-1.82(0.069)$ & -0.00238 & 0.00488 & -0.49 \\
\hline Digit span & -0.02536 & 0.09852 & -0.24 & -0.06086 & 0.10190 & -0.60 & 0.00962 & 0.44480 & $-0.02(0.983)$ & -0.08397 & 0.05594 & -1.5 \\
\hline Stroop & -0.00002 & 0.00023 & -0.07 & 0.00021 & 0.00024 & 0.90 & 0.00050 & 0.00103 & $0.49(0.625)$ & 0.00007 & 0.00013 & 0.57 \\
\hline Vocabulary & -0.00695 & 0.00253 & $-2.75^{\star}$ & -0.00718 & 0.00261 & $-2.75^{\star}$ & -0.02007 & 0.01110 & $-1.78(0.071)$ & -0.00284 & 0.00144 & -1.98 \\
\hline
\end{tabular}

Random intercepts for subjects and items, as well as random slopes for semantic $\times$ syntactic interference manipulations were included.

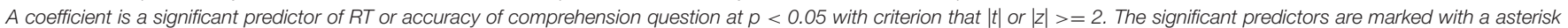
and also highlighted in red color.

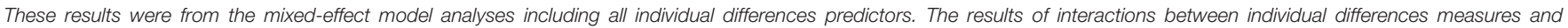
semantic/syntactic interference effect are reported in a separate table (see Table 7.)

TABLE 7 | Interaction of semantic/syntactic interference effect and individual differences measures in linear mixed-effects models with all predictors on the reading time and accuracy data.

\begin{tabular}{|c|c|c|c|c|c|c|c|}
\hline \multirow[t]{2}{*}{ DV } & \multirow[t]{2}{*}{ Predictor } & \multicolumn{3}{|c|}{ Semantic interference } & \multicolumn{3}{|c|}{ Syntactic interference } \\
\hline & & Coefficient & SE & $t$-score & Coefficient & SE & $t$-score \\
\hline \multirow[t]{5}{*}{ Critical (RT) } & Category & -0.03348 & 0.02945 & -1.14 & 0.03008 & 0.02884 & 1.04 \\
\hline & WM composite & 0.00180 & 0.00138 & 1.31 & -0.00280 & 0.00134 & $-2.09^{\star}$ \\
\hline & Digit & -0.00826 & 0.01571 & -0.53 & 0.01397 & 0.01532 & 0.91 \\
\hline & Stroop & -0.00003 & 0.00004 & -0.72 & -0.00002 & 0.00004 & -0.57 \\
\hline & Vocabulary & -0.00002 & 0.00040 & -0.05 & 0.00037 & 0.00039 & 0.93 \\
\hline \multirow[t]{5}{*}{ Spillover (RT) } & Category & -0.01438 & 0.02981 & -0.480 & -0.00747 & 0.02780 & -0.27 \\
\hline & WM composite & 0.00138 & 0.00140 & 0.990 & -0.00319 & 0.00129 & $-2.47^{\star}$ \\
\hline & Digit & -0.00897 & 0.01596 & -0.560 & 0.03344 & 0.01474 & $2.27^{*}$ \\
\hline & Stroop & 0.00004 & 0.00004 & 1.050 & -0.00001 & 0.00003 & -0.43 \\
\hline & Vocabulary & -0.00015 & 0.00041 & -0.370 & -0.00011 & 0.00038 & -0.30 \\
\hline \multirow[t]{6}{*}{ Question (RT) } & Category & -0.05930 & 0.02570 & $-2.31^{\star}$ & -0.00572 & 0.02348 & -0.24 \\
\hline & WM composite & 0.00005 & 0.00120 & 0.04 & 0.00030 & 0.00108 & 0.28 \\
\hline & Digit & -0.02306 & 0.01377 & -1.67 & -0.02018 & 0.01236 & -1.63 \\
\hline & Stroop & -0.00003 & 0.00003 & -0.84 & 0.00002 & 0.00003 & 0.64 \\
\hline & Vocabulary & -0.00036 & 0.00035 & -1.04 & 0.00037 & 0.00032 & 1.15 \\
\hline & & Coefficient & SE & $z$-score (p-value) & Coefficient & SE & $z$-score ( $p$-value) \\
\hline \multirow[t]{5}{*}{ Question (Error rates) } & Category & -0.03065 & 0.50950 & $-0.06(0.95)$ & 0.42810 & 0.53350 & $0.80(0.42)$ \\
\hline & WM composite & -0.04828 & 0.02271 & $-2.13^{\star}(0.03)$ & -0.00786 & 0.02350 & $-0.34(0.74)$ \\
\hline & Digit & 0.29550 & 0.28140 & $1.05(0.29)$ & 0.25620 & 0.29130 & $0.88(0.38)$ \\
\hline & Stroop & -0.00057 & 0.00063 & $-0.90(0.37)$ & -0.00002 & 0.00066 & $-0.03(0.98)$ \\
\hline & Vocabulary & 0.01421 & 0.00669 & $2.12^{\star}(0.03)$ & 0.00632 & 0.00714 & $0.89(0.37)$ \\
\hline
\end{tabular}

Vocabulary was included as a control variable. A coefficient is a significant predictor of $R T$ or accuracy of comprehension question at $p<0.05$ with criterion that $|t|>=2$ or $|z|>=2$. The significant predictors are marked with a asterisk and also highlighted in red color. 


\section{A Self-paced reading time}

\section{a1. Critical region ("will visit")}

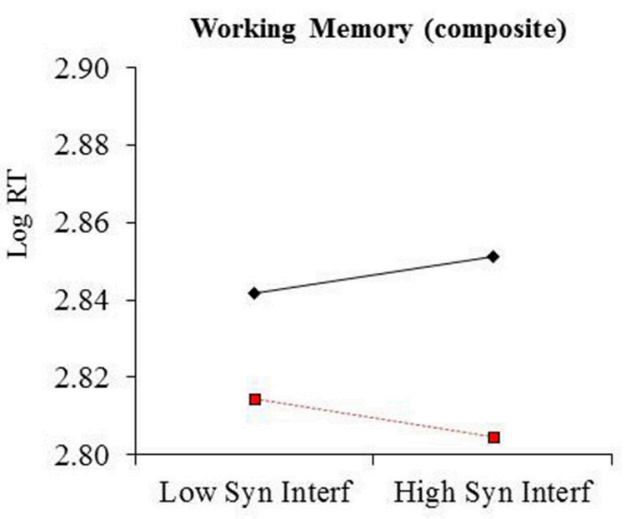

B Comprehension question ("Who will visit?")

\section{b1. Speed}

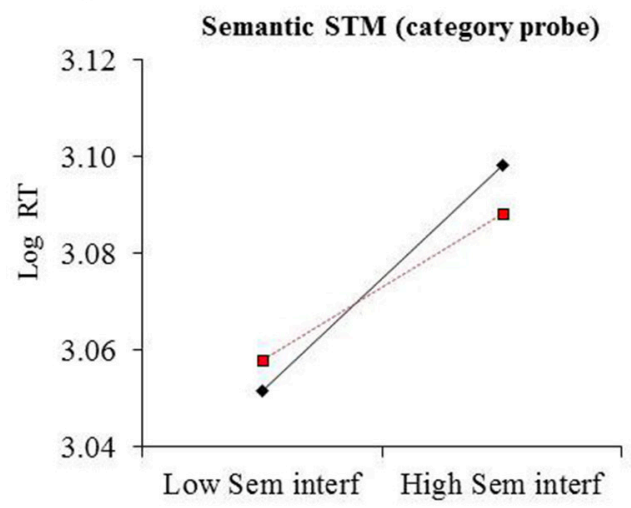

\section{b2. Error rates}

\section{Working Memory (composite)}

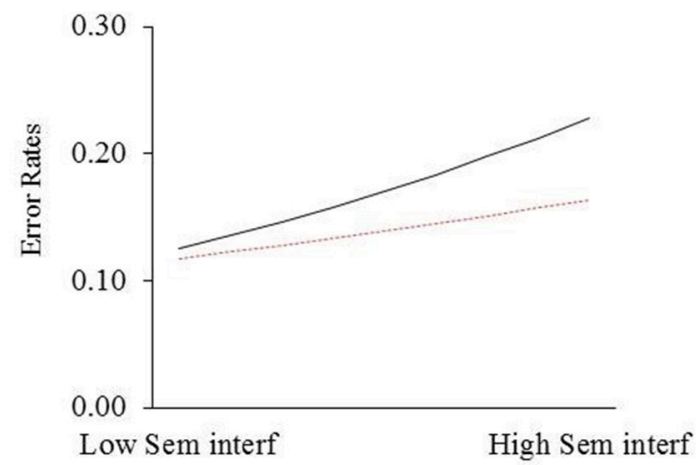

\section{a2. Spillover region ("the director")}

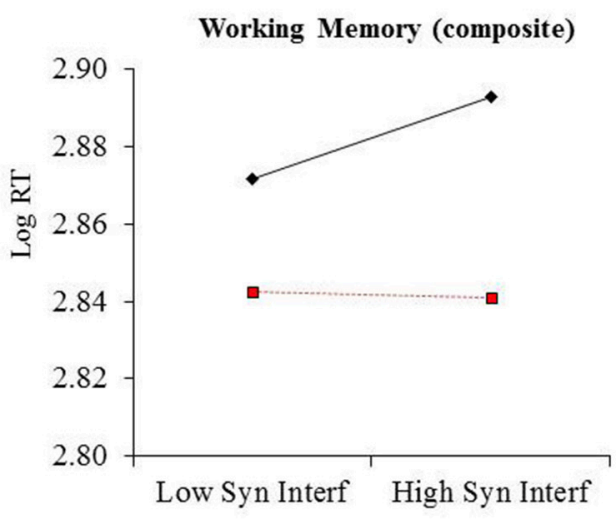

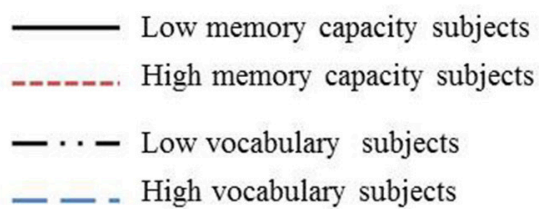

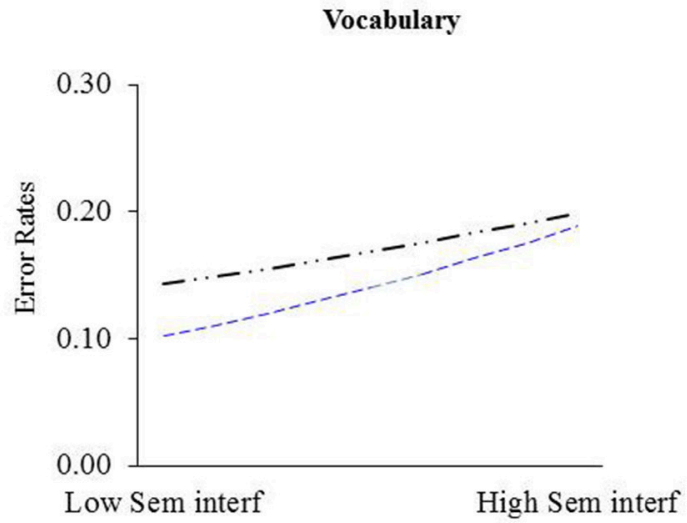

FIGURE 1 | Significant interactions in mixed-effects analysis for individual differences measure with interference effects (see Dawson, 2014, for plotting methods). For RTs $(\mathbf{a} 1, \mathbf{a} 2, \mathbf{b} 1)$, the points plotted for low and high capacity subjects are for -1 and +1 standard deviation from the mean on the composite WM measure or semantic STM measure. For error rates (b2), the values of the interference effect size (on x-axis), ranging from (-1.5) to (1.5) standard deviations from the mean, were calculated in 0.25 std units, with a line fitted to these effects. Panels $(\mathbf{a 1 , a 2 )}$ show the Syntactic interference $\times$ WM composite score interaction in self-paced reading time (ms) in the critical region ("will visit") and the spillover region ("the director"), respectively. Panel (b1) shows the Semantic interference $\times$ Category probe interaction in question answering speed. Panel (b2) shows the Semantic interference $\times$ WM composite and Semantic interference $\times$ Vocabulary interactions in question answering error rates. The scatter plots with data points from each subject are shown in Appendix G in Supplementary Material. 
Material (which presents single variable models with vocabulary as a control variable), when vocabulary and Stroop were included in a model without the other STM or WM measures, no significant interactions were observed with syntactic or semantic interference for either measure (all $t \mathrm{~s}<1$ ).

\section{Comprehension Questions}

\section{Model 2 (offline measures)}

The results of main effects and interactions of both experimental manipulations and individual differences measures are shown in Tables 6, 7. For comprehension question error rates, the mixedeffects analysis revealed significant main effects of both syntactic and semantic interference, with a higher error rate for the HiSyn compared to the LoSyn conditions ( 0.15 vs. 0.10 ), and a higher error rate for the HiSem compared to the LoSem conditions ( 0.15 vs. 0.10). The interaction of semantic and syntactic interference was not significant. For question answering RTs, there was a significant main effect of syntactic interference with slower responses in the HiSyn than the LoSyn condition (1,359 vs. 1,325 $\mathrm{ms})$, and a main effect of semantic interference, with slower responses in the HiSem condition than the LoSem condition (1,411 vs. $1,273 \mathrm{~ms})$. The interaction was not significant.

With respect to the individual differences interactions of primary interest, for RTs, there was a reliable interaction between the semantic interference effect and category probe span $(t=$ $-2.31)^{4}$, indicating that participants with better semantic STM were less distracted by a semantically plausible intervening NP in the HiSem conditions (as shown in Figure 1b1), even after controlling for vocabulary. None of the interactions with other individual differences measures was significant. For error rates, the interaction between the composite WM measure and semantic interference was significant $(t=-2.13, p=0.03)$, such that those with higher WM capacity showed smaller semantic interference effects. There was also a significant interaction between vocabulary and semantic interference $(t=2.12, p=$ 0.03 ), with those with higher vocabulary scores showing larger interference effects, which was opposite the effect reported in Van Dyke et al. (2014). Both interactions are displayed in Figure 1b2. Unlike the case for digit span, the negative weight for the interaction with vocabulary could not be attributed to a suppressor effect, as the same pattern was obtained in the model with vocabulary as a single predictor (see Appendix B in Supplementary Material). One might postulate that those with larger vocabularies have tighter links among concepts, resulting in greater spreading activation and more interference. It is not transparent why those with greater vocabularies showed larger interference effects in the present study whereas in the Van Dyke et al. (2014) study, those with larger vocabularies were less affected by an interfering external load. Of course, there are many differences in the two studies including the type of manipulation (i.e., external load vs. sentence-internal interference), the sentence structures, and the measure of

\footnotetext{
${ }^{4}$ To make the results more comprehensible in that the interpretation of the direction of coefficients would be the same for RTs and accuracy, we used error rates rather than accuracy in the analyses. Therefore, a negative coefficient for the interaction between error rates and the individual differences measures indicates that participants with better ability were more resistant to interference.
}

vocabulary (i.e., expressive vs. receptive vocabulary). Thus, future work would be needed to tease apart the source of the difference pattern of effects for vocabulary.

\section{Summary of question answering effects}

Robust effects of semantic and syntactic interference were observed for both RTs and error rates in question answering. For question answering speed, an interaction between the semantic STM measure (category probe) and semantic interference was obtained. For question answering error rates, the interaction between semantic interference and the composite WM measure, and the interaction between semantic interference and vocabulary were significant ${ }^{5}$.

\section{DISCUSSION}

Overall, these results provided further evidence demonstrating both syntactic and semantic interference effects during sentence processing (Van Dyke and Lewis, 2003; Van Dyke and McElree, 2006, 2011; Van Dyke, 2007; Glaser et al., 2013; Van Dyke et al., 2014). Participants were slower to read phrases and less accurate and slower to answer comprehension questions with high semantic or syntactic interference.

Of particular interest for the current study are the implications of the interactions between individual differences measures and sensitivity to interference for theories of the relation between WM and sentence processing (see Table 1). Table 8 indicates the significant interactions that were obtained. The discovery of an interaction of syntactic interference with the WM composite in reading times is an important finding, as no study has yet examined individual differences with respect to this type of interference. This finding is inconsistent with both the general WM and language-specific WM approaches. That is, the general WM approach predicted interactions between the composite WM measure and both syntactic and semantic interference during online processing and question answering, whereas the language-specific approach would not have predicted WM to be related to either type of interference in online measures.

With respect to the multiple capacities approach, the results were mixed. Consistent with this approach, the category probe measure of semantic STM interacted significantly with semantic

\footnotetext{
${ }^{5}$ While the main effects of the individual differences measures were not a focus of this study, there were some findings of interest. For online sentence comprehension, there was a main effect of vocabulary, indicating that subjects with better vocabularies read more quickly overall (critical verb region, $t=-2.75$; spillover region, $t=-2.75$ ), consistent with previous studies showing that highvocabulary subjects are generally more efficient in sentence reading (Perfetti, 2007; Traxler and Tooley, 2007; Kuperman and Van Dyke, 2011; Van Dyke and Shankweiler, 2013). In contrast, a positive effect of category probe was found (critical verb region, $t=3.27$; spillover region, $t=2.18$ ), indicating that subjects with better semantic STM read slower than subjects with poorer semantic STM for all conditions, possibly because the subjects with better semantic STM were more likely to detect the presence of two preceding nouns that might serve as the matrix verb subject. The main effects of digit span, Stroop, and the composite WM measure were not significant. For offline measures, only a significant main effect of category probe was observed in the accuracy data, indicating that individuals with better semantic STM capacity were more accurate in answering comprehension questions overall $(z=2.53, p=0.01)$.
} 
TABLE 8 | Significant interactions between self-paced reading and individual differences measures.

\begin{tabular}{|c|c|c|c|c|}
\hline & \multicolumn{2}{|c|}{ Self-paced reading } & \multicolumn{2}{|c|}{ Question answering } \\
\hline & RT (critical) & RT (spillover) & RT (question) & Accuracy \\
\hline \multicolumn{5}{|c|}{ SYNTACTIC INTERFERENCE } \\
\hline × WM Composite & * & * & & \\
\hline \multicolumn{5}{|l|}{$\times$ Category probe } \\
\hline × Digit span & & ${ }^{*}(-)$ & & \\
\hline \multicolumn{5}{|l|}{$\times$ Vocabulary } \\
\hline \multicolumn{5}{|l|}{ × Stroop } \\
\hline \multicolumn{5}{|c|}{ SEMANTIC INTERFERENCE } \\
\hline × WM Composite & & & & * \\
\hline$\times$ Category probe & & & * & \\
\hline \multicolumn{5}{|l|}{ × Digit span } \\
\hline × Vocabulary & & & & ${ }^{*}(-)$ \\
\hline × Stroop & & & & \\
\hline
\end{tabular}

Asterisks followed by a minus sign indicate interactions that went in the direction opposite that predicted.

but not syntactic interference in question answering RTs, even when a measure of verbal knowledge (i.e., WAIS vocabulary) was included as a control variable. Thus, semantic capacity per se beyond semantic knowledge related to semantic interference. Moreover, the measure of phonological retention (digit span) did not interact in the predicted direction with any measure. The specific relation of the composite WM measure to syntactic but not semantic interference sensitivity in self-paced reading might also be seen as consistent with the multiple capacities view, to the extent that the complex span measures tap a retention capacity that is more relevant to syntactic than semantic processing. However, the interaction of the complex span measure, but not the semantic STM measure, with semantic interference in accuracy is inconsistent with this view.

The results with respect to the cue-based parsing approach are also mixed. The significant interaction between syntactic interference and the WM composite in the critical and spillover regions, together with the interaction of complex span with semantic interference in question answering, appear to contradict the assertion that WM capacity per se is not involved in sentence processing (e.g., McElree et al., 2003; Van Dyke et al., 2014). The Van Dyke et al. study, which is the only other study to examine individual differences in sensitivity to interference, albeit semantic interference from distractors outside the sentence, did not find an interaction with IQ-partialled complex span tasks, however they did observe an interaction with IQ, which shares significant variance with complex span measures. Thus, it is possible that the effects observed here are tapping the variance shared between WM and IQ. Further research is needed to determine the nature of this variance.

The other primary result in the Van Dyke et al. (2014) study was to emphasize the quality of linguistic representations, as measured by an assessment of receptive vocabulary, as a factor in determining retrieval success. On the basis of this, we hypothesized that verbal knowledge (as assessed by WAIS vocabulary) may be related to either syntactic or semantic interference or both. We found some evidence for such a claim, as we found that vocabulary did interact with semantic interference, though only in questioning answering and with an effect in the opposite direction to that expected (i.e., higher vocabulary subjects showed greater interference). We nevertheless interpret the significant result as supporting the suggestion that qualitative aspects of the to-be-retrieved representations contribute to the size of interference effects. Additionally, a role for another general ability measure related to interference resolution ability (i.e., the Stroop effect) might have been expected on the cue-based parsing approach, but this failed to interact with interference in any dependent measure. This is discussed further below.

An issue for all models is that, as shown in Table 8, the interactions between syntactic interference and capacity measures only appeared during sentence reading, whereas those for semantic interference only appeared during question answering. The failure to find an interaction between semantic interference and any individual differences measure during online processing is somewhat surprising given that a significant $47 \mathrm{~ms}$ semantic interference effect was obtained in the spillover region; however, this null interaction with individual differences measures was also reported in an earlier study (Van Dyke et al., 2014). The significant interaction in question answering RT between category probe and semantic interference might be taken to imply that semantic STM or WM capacity only comes into play in offline semantic processing (e.g., in reviewing the sentence interpretation before answering a question). However, it is possible that the question answering effects reflect online processes that were begun earlier, but were not complete until past the end of the sentence. This is plausible given that the integration of semantic information appears to be slower than that for syntactic information (McElree and Griffith, 1995, 1998; Boland and Blodgett, 2001; Friederici, 2002; Hagoort, 2003). The difference in time course could be due to the finite set of grammatical features to be considered vs. the more complex considerations involved in determining semantic fit (e.g., "the play arrives" may be plausible even though "play" is inanimate). In addition, an important point to note for the present paradigm is that the correct resolution of semantic interference depends on using discriminative syntactic cues. That is, further consideration of semantic features will not resolve the semantic interference between two nouns if both are equally plausible as the subject of the verb. Therefore, perhaps the later time course for semantic interaction effects occurs because semantic conflict attracts attention to semantic features, whereas resolution of the conflict involves a shift of attention to syntactic features ${ }^{6}$.

\footnotetext{
${ }^{6}$ The resolution of semantic interference depends on using discriminative syntactic cues. For example, in the high-semantic, low-syntactic interference condition, the syntactic feature of subject or object is sufficient to determine the correct noun. While in the high-semantic, high-syntactic interference condition where both nouns are subjects, the appropriate noun can only be selected based on its not having been assigned as the subject of another verb. In contrast, for syntactic interference, syntactic conflict may mainly attract attention to syntactic features and it is these features that are needed to resolve the conflict. Therefore, the attention shift from semantic features to syntactic features results in delayed semantic interference resolution as compared to syntactic interference resolution, during which no attention shift is necessary. However, it should be noted that in many other sentence types, semantic and syntactic processes are
} 


\section{The Complexity of WM Capacity and Implications for Sentence Processing Theories}

As discussed in the introduction, early studies relating complex span measures like reading span to sentence processing assumed that these measures reflected a single capacity that could be flexibly allocated to storage or processing (Daneman and Carpenter, 1980; Just and Carpenter, 1992). However, recent studies argue against the assumption that WM capacity reflects a unitary capacity. Both Shipstead et al. (2014) and Unsworth et al. (2014) concluded, on the basis of large scale individual differences studies, that WM capacity can be divided into three components reflecting primary memory capacity (i.e., the capacity for maintaining information in the focus of attention), attentional control, and the ability to retrieve information from outside the focus of attention (i.e., from secondary memory). Secondary memory retrieval ability was not assessed in the present study and thus we cannot comment on its potential contribution to interactions of WM capacity with sensitivity to syntactic and semantic interference. Although, digit span may not be an ideal measure of primary memory capacity, it is highly correlated with other measures that have been argued to reflect this capacity (e.g., running span; Cowan et al., 2005). Thus, the significant interaction of WM capacity with syntactic interference even with digit span in the model suggests that the influence of WM capacity does not reflect the influence of primary memory capacity. An obvious candidate for explaining the relevant shared variance between WM capacity and interference resolution that would be consistent within the cue-based retrieval framework is attentional control. This hypothesis could also explain the link observed between WM capacity as measured by the complex WM tasks and the efficiency of controlled memory retrieval in previous memory studies (Öztekin and McElree, 2010; Mizrak and Öztekin, 2016). Öztekin and McElree found that low-WM span subjects took longer for the controlled retrieval of episodic information as compared to high-WM span subjects. As they suggested that there should be no differences in subjects' primary memory capacity (or the limit of focus of attention) assuming both groups could only maintain 1 -item, such a relation might reflect better attentional control for high WM span subjects.

However, no interactions with our measure most related to attentional control-Stroop interference-were observed in the current study. It is possible, though, that the Stroop effect is not the most appropriate measure of this capacity. Of note is the fact that in the Shipstead et al. (2014) study the Stroop effect had the lowest weight on the attentional control factor out of the three variables used to tap that construct (the other two being anti-saccade and flanker tests). Particularly for sentence parsing, the type of inhibition required for Stroop (inhibition of a prepotent response) may not be the same as the inhibition required to resolve interference from incorrectly retrieved information during sentence processing (see Friedman and Miyake, 2004). This may be more consistent with either

relatively independent and separable. The processing of semantic information does not always depend on the processing of syntactic information (e.g., Kim and Osterhout, 2005). a mechanism supporting selection from a range of partially matching competitors (e.g., Thompson-Schill et al., 1997; Novick et al., 2005), or reanalysis, involving rejection of an incorrectly retrieved item or incorrectly constructed dependency (Van Dyke and Lewis, 2003). In neither of these cases is there a prepotent response, and so it is perhaps not surprising that we failed to find this association with the Stroop effect. Clearly, however, future work would be needed to show that other measures of interference resolution ability, particularly those involved in the resolution of proactive interference (Friedman and Miyake, 2004; Pettigrew and Martin, 2014), do relate to syntactic and semantic interference effects. Ideally, such a study would also include measures of primary memory capacity and the ability to retrieve information from secondary memory, as cue-based retrieval from outside the focus of attention is a crucial component of the cue-based parsing approach. Thus, a finding that general secondary memory retrieval abilities are related to the resolution of interference in sentence processing would also be supportive of this view.

The relation of category probe span, a STM measure, to semantic interference may suggest that differences in aspects of primary memory do affect interference resolution in a codespecific manner. This result is consistent with finding in the WM literature indicating a role for modality-specific retention abilities, in addition to general WM capacity, in a variety of cognitive domains (See Conway and Kovacs, 2013). As the cuebased parsing approach has argued that primary memory has a capacity fixed to 1-2 items in the current focus of attention (e.g., Lewis et al., 2006), the findings for category probe were not predicted from this theoretical approach. However, within the cue-based parsing framework, this finding could be interpreted as reflecting individual differences in the rate at which semantic features may be reactivated or become lost outside the focus of attention. Moreover, the fact that this measure does not interact with syntactic interference may imply that the rate of feature loss is different for semantic and syntactic information. This view is equivalent to the assumption in the multiple capacities approach of different capacities for semantic and syntactic informationframing it instead in terms of the rate of feature loss instead of buffer capacity (Martin and Romani, 1994; Martin and He, 2004). Thus, we might expect that a separate measure of syntactic retention-if such could be identified-would relate to syntactic interference, with the size of the syntactic interference effect being determined by the rate at which syntactic features are reactivated or lost.

\section{CONCLUSIONS}

In line with prior studies, our study demonstrated semantic and syntactic interference from unavailable constituents during sentence processing, consistent with the cue-based parsing approach. The novel aspect of the present study was the investigation of the role of individual differences in WM in modulating these interference effects. We found that general WM capacity derived from complex span tasks showed a relation to syntactic interference during online sentence processing, and to 
semantic interference during question answering. In addition, a measure of semantic STM capacity predicted the size of semantic but not syntactic interference effects in question answering, while phonological capacity did not predict the size of any interference effects. These interactions with WM were observed in both online and offline processing, even when controlling for vocabulary differences.

The pattern of results argues against claims that a specialized $\mathrm{WM}$ is involved in sentence parsing that is different from the capacities tapped by standard simple or complex span measures (Caplan and Waters, 1999). We speculate that the relations to general WM capacity reflect the role controlled attention and potentially secondary memory retrieval involved in both complex span measures and in resolving interference during sentence comprehension. In addition, we consider the specific relation between semantic STM and semantic interference as an indication that code-specific retention capacities mediate resolution and that the rate of loss of semantic or syntactic features (if such could be measured) may differ separately across individuals. This latter assumption is consistent with the multiple capacities approach to WM in which there are separable syntactic and semantic capacities, with the rate of loss of featural information replacing the notion of capacity limits.

\section{LIMITATIONS AND FUTURE DIRECTIONS}

There are limitations to the current study, which could be addressed by future research. Most of these were mentioned earlier, but will be summarized here. First, the multiple capacities approach assumes a separable syntactic capacity, but no specific measure of that capacity was included here. In future work, it would be important to include a measure of the ability to retain syntactic information per se, which would have to be demonstrated to be separable from semantic retention and general working memory capacity. Second, with respect to the cue-based parsing approach, despite the proposal that WM capacity may be so limited as to be irrelevant for parsing, we did nevertheless observe significant relationships between our measure of general WM capacity and comprehension. In the face of data pointing to a highly limited WM capacity for sentence processing (e.g., McElree et al., 2003; Johns et al., 2015), future research will need to address the question of what these measures represent, if not capacity. We have noted that recent research with WM capacity as measured by complex span tasks has suggested that separate mechanisms of maintenance in primary memory (which seems equivalent to the focus of attention), attentional control, and retrieval from long-term memory (e.g., Shipstead et al., 2014; Unsworth et al., 2014) underlie this construct. Future work will need to sort out which of these is the source of the relation between general

\section{REFERENCES}

Acheson, D. J., and MacDonald, M. C. (2011). The rhymes that the reader perused confused the meaning: phonological effects during on-line sentence comprehension. J. Mem. Lang. 65, 193-207. doi: 10.1016/j.jml.2011.04.006
WM and sentence processing observed here. Here we suggested that attentional control may underlie our findings, but did not measure this capacity directly. This would be important to do. In particular, it will be important to test whether effects of WM capacity would disappear when a measure of the ability to resolve proactive interference (which is distinct from the ability to resolve response/distractor interference as in Stroop; Friedman and Miyake, 2004) is modeled. Finally, given the differences between some of the results obtained here and those reported elsewhere (such as the influence of vocabulary on the direction of interference effects), future work will be needed to understand the extent to which the relationship between WM, vocabulary, and interference resolution depends on the type of task (dual-task vs. standard reading) or the location of distractors (sentence-internal vs. sentence-external).

\section{ETHICS STATEMENT}

This study was carried out in accordance with the recommendations of the Rice University Institutional Review Board with written informed consent from all subjects. All subjects gave written informed consent in accordance with the Declaration of Helsinki. The protocol was approved by the Rice University Institutional Review Board.

\section{AUTHOR CONTRIBUTIONS}

Conception or design of the work: YT, RM, and JV. Data collection: YT. Data analysis and interpretation: YT, RM, and JV. Drafting the article: YT and RM. Critical revision of the article: YT, RM, and JV. Final approval of the version to be published: YT, RM, and JV.

\section{ACKNOWLEDGMENTS}

This work was supported by the Social Sciences Research Institute and the Gertrude Maurin Fund at Rice University and by NIH grant HD 073288 National Institute of Child Health and Human Development to Haskins Laboratories: (JV, PI). The authors are grateful to Clinton L. Johns and Dave Kush for thoughtful discussions of these results. The content is solely the responsibility of the authors and does not necessarily represent the official views of the National Institutes of Health.

\section{SUPPLEMENTARY MATERIAL}

The Supplementary Material for this article can be found online at: http://journal.frontiersin.org/article/10.3389/fpsyg. 2017.00198/full\#supplementary-material

Baayen, R. H. (2008). Analyzing Linguistic Data: A Practical Introduction to Statistics Using R. Cambridge: Cambridge University Press.

Baayen, R. H. (2011). languageR: Data Sets and Functions with Analyzing Linguistic Data: A Practical Introduction To Statistics. R Package Version 1.2. Cambridge: Cambridge University Press 
Baayen, R. H., Davidson, D. J., and Bates, D. M. (2008). Mixed-effects modeling with crossed random effects for subjects and items. J. Mem. Lang. 59, 390-412. doi: 10.1016/j.jml.2007.12.005

Baayen, R. H., and Milin, P. (2010). Analyzing reaction times. Int. J. Psychol. Res. $3,12-28$.

Baddeley, A., Gathercole, S., and Papagno, C. (1998). The phonological loop as a language learning device. Psychol. Rev. 105, 158-173. doi: 10.1037/0033-295X.105.1.158

Barde, L. H. F., Schwartz, M. F., Chrysikou, E. G., and Thompson-Schill, S. L. (2010). Reduced STM span in aphasia and susceptibility to interference: contribution of material-specific maintenance deficits. Neuropsychologia 48, 909-920. doi: 10.1016/j.neuropsychologia.2009.11.010

Barr, D. J., Levy, R., Scheepers, C., and Tily, H. J. (2013). Random effects structure for confirmatory hypothesis testing: keep it maximal. J. Mem. Lang. 68, 255-278. doi: 10.1016/j.jml.2012.11.001

Bartek, B., Lewis, R. L., Vasishth, S., and Smith, M. R. (2011). In search of online locality effects in sentence comprehension. J. Exp. Psychol. 37, 1178-1198. doi: $10.1037 / \mathrm{a} 0024194$

Boland, J. E., and Blodgett, A. (2001). Understanding the constraints on syntactic generation: lexical bias and discourse congruency effects on eye movements. J. Mem. Lang. 45, 381-411. doi: 10.1006/jmla.2000.2778

Camos, V., Mora, G., and Barrouillet, P. (2013). Phonological similarity effect in complex span task. Q. J. Exp. Psychol. 66, 1927-1950. doi: 10.1080/17470218.2013.768275

Camos, V., Mora, G., and Oberauer, K. (2011). Adaptive choice between articulatory rehearsal and attentional refreshing in verbal WM. Mem. Cogn. 39, 231-244. doi: 10.3758/s13421-010-0011-x

Caplan, D., Michaud, J., and Hufford, R. (2013). Short-term memory, WM, and syntactic comprehension in aphasia. Cogn. Neuropsychol. 30, 77-109. doi: 10.1080/02643294.2013.803958

Caplan, D., and Waters, G. (2013). Memory mechanisms supporting syntactic comprehension. Psychon. Bull. Rev. 20, 243-268. doi: 10.3758/s13423-012-0369-9

Caplan, D., and Waters, G. S. (1999). Verbal WM and sentence comprehension. Behav. Brain Sci. 22, 77-94. doi: 10.1017/S0140525X99001788

Cohen, J. D., MacWhinney, B., Flatt, M., and Provost, J. (1993). PsyScope: a new graphic interactive environment for designing psychology experiments. Behav. Res. Methods Instrum. Comput. 25, 257-271. doi: 10.3758/BF03204507

Conway, A. R., and Kovacs, K. (2013). Individual differences in intelligence and WM: a review of latent variable models. Psychol. Learn. Motiv. 58, 233-270. doi: 10.1016/B978-0-12-407237-4.00007-4

Cowan, N. (1999). “An embedded-process model of WM," in Models of WM. Mechanisms of Active Maintenance and Executive Control, eds A. Miyake and P. Shah (Cambridge, England: Cambridge University Press), 62-101.

Cowan, N. (2000). The magical number 4 in STM: a reconsideration of mental storage capacity. Behav. Brain Sci. 24, 87-114. doi: $10.1017 /$ S0140525X01003922

Cowan, N. (2011). The focus of attention as observed in visual working memory tasks: making sense of competing claims. Neuropsychologia 49, 1401-1406. doi: 10.1016/j.neuropsychologia.2011.01.035

Cowan, N., Elliott, E. M., Saults, J. S., Morey, C. C., Mattox, S., Hismjatullina, A., et al. (2005). On the capacity of attention: its estimation and its role in WM and cognitive aptitudes. Cogn. Psychol. 51, 42-100. doi: 10.1016/j.cogpsych.2004.12.001

Cronbach, L. J. (1951). Coefficient alpha and the internal structure of tests. Psychometrika 16, 297-334. doi: 10.1007/BF02310555

Daneman, M., and Carpenter, P. (1980). Individual differences in WM and reading. J. Verbal Learn. Verbal Behav. 19, 450-466. doi: 10.1016/S0022-5371(80)90312-6

Daneman, M., and Hannon, B. (2007). "What do WM span tasks like reading span really measure?" in The Cognitive Neuroscience of Working Memory, eds N. Osaka, R. H. Logie, and M. D'Esposito (Oxford, UK: Oxford University Press), 21-42.

Daneman, M., and Merikle, P. M. (1996). Working memory and language comprehension: a meta-analysis. Psychon. Bull. Rev. 3, 422-433. doi: 10.3758/BF03214546

Dawson, J. F. (2014). Moderation in management research: what, why, when, and how. J. Bus. Psychol. 29, 1-19. doi: 10.1007/s10869-013-9308-7
Dunn, L. M., and Dunn, L. M. (1997). Peabody Picture Vocabulary Test, 3rd Edn. Circle Pines, MN: American Guidance Services.

Engle, R. W. (2002). Working memory capacity as executive attention. Curr. Dir. Psychol. Sci. 11, 19-23. doi: 10.1111/1467-8721.00160

Engle, R. W., and Kane, M. J. (2004). Executive attention, WM capacity, and a two-factor theory of cognitive control. Psychol. Learn. Motiv. 44, 145-200. doi: 10.1016/S0079-7421(03)44005-X

Engle, R. W., Kane, M. J., and Tuholski, S. W. (1999a). Individual differences in WM capacity and what they tell us about controlled attention, general fluid intelligence, and functions of the prefrontal cortex. Models of WM: Mechanisms of active maintenance and executive control, 102-134.

Engle, R. W., Tuholski, S. W., Laughlin, J. E., and Conway, A. R. (1999b). Working memory, STM, and general fluid intelligence: a latent-variable approach. J. Exp. Psychol. Gen. 128:309. doi: 10.1037/0096-3445.128.3.309

Evans, W. S., Caplan, D., Ostrowski, A., Michaud, J., Guarino, A. J., and Waters, G. (2015). Working memory and the revision of syntactic and discourse ambiguities. Can. J. Exp. Psychol. 69, 136-155. doi: 10.1037/cep0000037

Fedorenko, E., Gibson, E., and Rohde, D. (2006). The nature of WM capacity in sentence comprehension: evidence against domain-specific WM resources. J. Mem. Lang. 54, 541-553. doi: 10.1016/j.jml.2005.12.006

Fedorenko, E., Gibson, E., and Rohde, D. (2007). The nature of WM in linguistic, arithmetic and spatial integration processes. J. Mem. Lang. 56, 246-269. doi: 10.1016/j.jml.2006.06.007

Friederici, A. D. (2002). Towards a neural basis of auditory sentence processing. Trends Cogn. Sci. 6, 78-84. doi: 10.1016/S1364-6613(00)01839-8

Friedmann, N., and Gvion, A. (2003). Sentence comprehension and WM limitation in aphasia: A dissociation between semantic-syntactic and phonological reactivation. Brain Lang. 86, 23-39. doi: 10.1016/S0093-934X(02)00530-8

Friedman, N. P., and Miyake, A. (2004). The relations among inhibition and interference resolution: a latent-variable analysis. J. Exp. Psychol. Gen. 133, 101-135. doi: 10.1037/0096-3445.133.1.101

Fry, A. F., and Hale, S. (1996). Processing speed, WM, and fluid intelligence: evidence for a developmental cascade. Psychol. Sci. 7, 237-241. doi: 10.1111/j.1467-9280.1996.tb00366.x

Gibson, E. A. (1998). Linguistic complexity: locality of syntactic dependencies. Cognition 68, 1-76. doi: 10.1016/S0010-0277(98)00034-1

Gibson, E. A. (2000). "The dependency locality theory: a distance-based theory of linguistic complexity," in Image, Language, Brain, eds Y. Miyashita, A. Mirantz, and W. O’Neil (Cambridge, MA: MIT Press), 95-126.

Glaser, Y. G., Martin, R. C., Van Dyke, J. A., Hamilton, A. C., and Tan, Y. (2013). Neural basis of semantic and syntactic interference in sentence comprehension. Brain Lang. 126, 314-326. doi: 10.1016/j.bandl.2013. 06.006

Gordon, P. C., Hendrick, R., and Johnson, M. (2001). Memory interference during language processing. J. Exp. Psychol. Learn. Mem. Cogn. 27:1411. doi: 10.1037/0278-7393.27.6.1411

Gordon, P. C., Hendrick, R., and Johnson, M. (2004). Effects of noun phrase type on sentence complexity. J. Mem. Lang. 51, 97-114. doi: 10.1016/j.jml.2004.02.003

Gordon, P. C., Hendrick, R., Johnson, M., and Lee, Y. (2006). Similaritybased interference during language comprehension: evidence from eye tracking during reading. J. Exp. Psychol. Learn. Mem. Cogn. 32, 1304-1321. doi: 10.1037/0278-7393.32.6.1304

Gordon, P. C., Hendrick, R., and Levine, W. H. (2002). Memory-load interference in syntactic processing. Psychol. Sci. 13, 425-430. doi: 10.1111/1467-9280.00475

Hagoort, P. (2003). Interplay between syntax and semantics during sentence comprehension: ERP effects of combining syntactic and semantic violations. J. Cogn. Neurosci. 15, 883-899. doi: 10.1162/089892903322370807

Hambrick, D. Z., Kane, M. J., and Engle, R. W. (2005). "The role of WM in higherlevel cognition," in Cognition and Intelligence: Identifying the Mechanisms of the Mind, eds R. J. Sternberg and J. E. Pretz (Cambridge: Cambridge University Press), 104-121.

Hamilton, A. C., and Martin, R. C. (2005). Dissociations among tasks involving inhibition: a single-case study. Cogn. Affect. Behav. Neurosci. 5, 1-13. doi: 10.3758/CABN.5.1.1

Hamilton, A. C., and Martin, R. C. (2007). Proactive interference in a semantic short-term memory deficit: role of semantic and phonological relatedness. Cortex 43, 112-123. doi: 10.1016/S0010-9452(08)70449-0 
Hamilton, A. C., Martin, R. C., and Burton, P. C. (2009). Converging functional magnetic resonance imaging evidence for a role of the left inferior frontal lobe in semantic retention during language comprehension. Cogn. Neuropsychol. 26, 685-704. doi: 10.1080/02643291003665688

Hanten, G., and Martin, R. C. (2000). Contributions of phonological and semantic STM to sentence processing: evidence from two cases of closed head injury in children. J. Mem. Lang. 43, 335-361. doi: 10.1006/jmla. 2000.2731

Harris, L., Olson, A., and Humphreys, G. (2013). Type-specific proactive interference in patients with semantic and phonological STM deficits. Memory 22, 972-989. doi: 10.1080/09658211.2013.860171

Harrison, T. L., Shipstead, Z., and Engle, R. W. (2015). Why is WM capacity related to matrix reasoning tasks? Mem. Cogn. 43, 389-396. doi: 10.3758/s13421-014-0473-3

Hsu, N. S., and Novick, J. M. (2016). Dynamic engagement of cognitive control modulates recovery from misinterpretation during real-time language processing. Psychol. Sci. 27, 572-582. doi: 10.1177/09567976156 25223

Jefferies, E., Baker, S. S., Doran, M., and Lambon Ralph, M. A. (2007). Refractory effects in stroke aphasia: a consequence of poor semantic control. Neuropsychologia 45, 1065-1079. doi: 10.1016/j.neuropsychologia.2006.09.009

Just, M. A., and Carpenter, P. A. (1992). A capacity theory of comprehension: individual differences in WM. Psychol. Rev. 99, 122-149. doi: 10.1037/0033-295X.99.1.122

Just, M. A., Carpenter, P. A., and Woolley, J. D. (1982). Paradigms and processes in reading comprehension. J. Exp. Psychol. Gen. 111, 228-238. doi: 10.1037/0096-3445.111.2.228

Johns, C. L., Matsuki, K., and Van Dyke, J. A. (2015). Poor readers' retrieval mechanism: efficient access is not dependent on reading skill. Front. Psychol. 6:1552. doi: 10.3389/fpsyg.2015.01552

Kane, M. J., Bleckley, M. K., Conway, A. R. A., and Engle, R. W. (2001). A controlled-attention view of working-memory capacity. J. Exp. Psychol. Gen. 130, 169-183. doi: 10.1037/0096-3445.130.2.169

Kane, M. J., Conway, A. R., Hambrick, D. Z., and Engle, R. W. (2007). "Variation in WM capacity as variation in executive attention and control," in Variation in Working Memory, Vol. 1, eds A. R. A, Conway, C. Jarrold, M. J. Kane, A. Miyake, and J. N. Towse (Oxford: Oxford University Press), 21-48.

Kane, M. J., and Engle, R. W. (2002). The role of prefrontal cortex in working-memory capacity, executive attention, and general fluid intelligence: an individual-differences perspective. Psychon. Bull. Rev. 9, 637-671. doi: $10.3758 / \mathrm{BF} 03196323$

Kane, M. J., and Engle, R. W. (2003). Working-memory capacity and the control of attention: the contributions of goal neglect, response competition, and task set to Stroop interference. J. Exp. Psychol. Gen. 132, 47-70. doi: 10.1037/0096-3445.132.1.47

Kim, A., and Osterhout, L. (2005). The independence of combinatory semantic processing: evidence from event-related potentials. J. Mem. Lang. 52, 205-225. doi: $10.1016 /$ j.jml.2004.10.002

King, J., and Just, M. A. (1991). Individual differences in syntactic processing: the role of WM. J. Mem. Lang. 30, 580-602. doi: 10.1016/0749-596X(91)90027-H

Kuperman, V., and Van Dyke, J. A. (2011). Effects of individual differences in verbal skills on eye-movement patterns during sentence reading. J. Mem. Lang. 65, 42-73. doi: 10.1016/j.jml.2011.03.002

Kush, D., Johns, C. L., and Van Dyke, J. A. (2015). Identifying the role of phonology in sentence-level reading. J. Mem. Lang. 79, 18-29. doi: 10.1016/j.jml.2014.11.001

Lewis, R. L. (1996). Interference in STM: the magical number two (or three) in sentence processing. J. Psycholinguist. Res. 25, 93-115. doi: $10.1007 / \mathrm{BF} 01708421$

Lewis, R. L., and Vasishth, S. (2005). An activation-based model of sentence processing as skilled memory retrieval. Cogn. Sci. 29, 375-419. doi: 10.1207/s15516709cog0000_25

Lewis, R. L., Vasishth, S., and Van Dyke, J. A. (2006). Computational principles of WM in sentence comprehension. Trends Cogn. Sci. 10, 447-454. doi: 10.1016/j.tics.2006.08.007

Long, D. L., Johns, C. L., and Morris, P. E. (2006). "Comprehension ability in mature readers," in Handbook of Psycholinguistics, eds M. Traxler and M. Gernsbacher (Burlington, MA: Academic Press), 801-834.
Martin, N., and Saffran, E. M. (1997). Language and auditory-verbal shortterm memory impairments: evidence for common underlying processes. Cogn. Neuropsychol. 14, 641-682. doi: 10.1080/026432997381402

Martin, R. C. (2005). Components of short-term memory and their relation to language processing evidence from neuropsychology and neuroimaging. Curr. Dir. Psychol. Sci. 14, 204-208. doi: 10.1111/j.0963-7214.2005.00365.x

Martin, R. C., and Freedman, M. L. (2001). Short-term retention of lexicalsemantic representations: implications for speech production. Memory 9, 261-280. doi: 10.1080/09658210143000173

Martin, R. C., and He, T. (2004). Semantic STM and its role in sentence processing: a replication. Brain Lang. 89, 76-82. doi: 10.1016/S0093-934X(03)00300-6

Martin, R. C., and Romani, C. (1994). Verbal WM and sentence comprehension: a multiple-components view. Neuropsychology 8, 506-523. doi: 10.1037/0894-4105.8.4.506

Martin, R. C., Shelton, J. R., and Yaffee, L. S. (1994). Language processing and WM: neuropsychological evidence for separate phonological and semantic capacities. J. Mem. Lang. 33, 83-111. doi: 10.1006/jmla.1994.1005

Martin, R. C., Lesch, M. F., and Bartha, M. C. (1999). Independence of input and output phonology in word processing and short-term memory. J. Mem. Lang. 41, 3-29. doi: 10.1006/jmla.1999.2637

Martin, R. C., Wu, D. H., Freedman, M. L., Jackson, E. F., and Lesch, M. (2003). An event-related fMRI investigation of phonological versus semantic STM. J. Neurolinguist. 16, 341-360. doi: 10.1016/S0911-6044(03)00025-3

McElree, B. (2000). Sentence comprehension is mediated by contentaddressable memory structures. J. Psycholinguist. Res. 29, 111-123. doi: 10.1023/A:1005184709695

McElree, B. (2006). Accessing recent events. Psychol. Learn. Motiv. 46, 155-200. doi: 10.1016/S0079-7421(06)46005-9

McElree, B., and Dosher, B. A. (1989). Serial position and set size in STM: the time course of recognition. J. Exp. Psychol. Gen. 118, 346-373. doi: 10.1037/0096-3445.118.4.346

McElree, B., Foraker, S., and Dyer, L. (2003). Memory structures that subserve sentence comprehension. J. Mem. Lang. 48, 67-91, doi: 10.1016/S0749-596X(02)00515-6

McElree, B., and Griffith, T. (1995). Syntactic and thematic processing in sentence comprehension: evidence for a temporal dissociation. J. Exp. Psychol. Learn. Mem. Cogn. 21, 134-157. doi: 10.1037/0278-7393.21.1.134

McElree, B., and Griffith, T. (1998). Structural and lexical constraints on filling gaps during sentence processing: a time-course analysis. J. Exp. Psychol. Learn. Mem. Cogn. 24, 432-460. doi: 10.1037/0278-7393.24.2.432

Mızrak, E., and Öztekin, I. (2016). Working memory capacity and controlled serial memory search. Cognition 153, 52-62. doi: 10.1016/j.cognition.2016.04.007

Novick, J. M., Hussey, E., Teubner-Rhodes, S., Harbison, J. I., and Bunting, M. F. (2014). Clearing the garden-path: improving sentence processing through cognitive control training. Lang. Cogn. Neurosci. 29, 186-217. doi: 10.1080/01690965.2012.758297

Novick, J. M., Kan, I. P., Trueswell, J. C., and Thompson-Schill, S. L. (2009). A case for conflict across multiple domains: memory and language impairments following damage to ventrolateral prefrontal cortex. Cogn. Neuropsychol. 26, 527-567. doi: 10.1080/02643290903519367

Novick, J. M., Trueswell, J. C., and Thompson-Schill, S. L. (2005). Cognitive control and parsing: reexamining the role of Broca's area in sentence comprehension. Cogn. Affect. Behav. Neurosci. 5, 263-281. doi: 10.3758/CABN.5.3.263

Nunnally, J. C., Bernstein, I. H., and Berge, J. M. T. (1967). Psychometric Theory, Vol. 226. New York, NY: McGraw-Hill.

Oberauer, K. (2002). Access to information in WM: exploring the focus of attention. J. Exp. Psychol. Learn. Mem. Cogn. 28, 411-421. doi: 10.1037/0278-7393.28.3.411

Öztekin, I., Davachi, L., and McElree, B. (2010). Are representations in working memory distinct from representations in long-term memory? Neural evidence in support of a single store. Psychol. Sci. 21, 1123-1133. doi: $10.1177 / 0956797610376651$

Öztekin, I., and McElree, B. (2010). Relationship between measures of working memory capacity and the time course of short-term memory retrieval and interference resolution. J. Exp. Psychol. Learn. Mem. Cogn. 36:383. doi: 10.1037/a0018029

Perfetti, C. A. (2007). Reading ability: lexical quality to comprehension. Sci. Stud. Read. 11, 357-383. doi: 10.1080/10888430701530730 
Pettigrew, C., and Hillis, A. E. (2014). Role for memory capacity in sentence comprehension: evidence from acute stroke. Aphasiology 28, 1258-1280. doi: 10.1080/02687038.2014.919436

Pettigrew, C., and Martin, R. C. (2014). Cognitive declines in healthy aging: evidence from multiple aspects of interference resolution. Psychol. Aging 29, 187-204. doi: 10.1037/a0036085

Redick, T. S., Broadway, J. M., Meier, M. E., Kuriakose, P. S., Unsworth, N., Kane, M. J., et al. (2012). Measuring WM capacity with automated complex span tasks. Eur. J. Psychol. Assess. 28, 164-171. doi: 10.1027/1015-5759/a000123

Salthouse, T. A., Atkinson, T. M., and Berish, D. E. (2003). Executive functioning as a potential mediator of age-related cognitive decline in normal adults. J. Exp. Psychol. Gen. 132, 566-594. doi: 10.1037/0096-3445.132.4.566

Schmitt, N. (1996). Uses and abuses of coefficient alpha. Psychol. Assess. 8, 350-353. doi: 10.1037/1040-3590.8.4.350

Schneider, W., Eschman, A., and Zuccolotto, A. (2002). E-Prime User's Guide. Pittsburgh, PA: Psychological Software Tools.

Shipstead, Z., Lindsey, D. R. B., Marshall, R. L., and Engle, R. W. (2014). The mechanisms of WM capacity: primary memory, secondary memory, and attention control. J. Mem. Lang. 72, 116-141. doi: 10.1016/j.jml.2014.01.004

Stroop, J. R. (1935). Studies of interference in serial verbal reactions. J. Exp. Psychol. 18, 643-662. doi: 10.1037/h0054651

Tabor, W., Galantucci, B., and Richardson, D. (2004). Effects of merely local syntactic coherence on sentence processing. J. Mem. Lang. 50, 355-370. doi: 10.1016/j.jml.2004.01.001

Thompson-Schill, S. L., D’Esposito, M., Aguirre, G. K., and Farah, M. J. (1997). Role of left inferior prefrontal cortex in retrieval of semantic knowledge: a reevaluation. Proc. Natl. Acad. Sci. U.S.A. 94, 14792-14797.

Traxler, M. J., and Tooley, K. M. (2007). Lexical mediation and context effects in sentence processing. Brain Res. 1146, 59-74. doi: $10.1016 /$ j.brainres.2006.10.010

Trueswell, J. C., Tanenhaus, M. K., and Garnsey, S. M. (1994). Semantic influences on parsing: use of thematic role information in syntactic ambiguity resolution. J. Mem. Lang. 33, 285-318. doi: 10.1006/jmla.1994.1014

Turner, M. L., and Engle, R. W. (1989). Is WM capacity task dependent? J. Mem. Lang. 28, 127-154. doi: 10.1016/0749-596X(89)90040-5

Unsworth, N., and Engle, R. W. (2007). On the division of short-term and WM: an examination of simple and complex span and their relation to higher order abilities. Psychol. Bull. 133, 1038-1066. doi: 10.1037/0033-2909.133.6.1038

Unsworth, N., Fukuda, K., Awh, E., and Vogel, E. K. (2014). Working memory and fluid intelligence: capacity, attention control, and secondary memory retrieval. Cogn. Psychol. 71, 1-26. doi: 10.1016/j.cogpsych.2014.01.003

Unsworth, N., Heitz, R. P., Schrock, J. C., and Engle, R. W. (2005). An automated version of the operation span task. Behav. Res. Methods 37, 498-505. doi: 10.3758/BF03192720

Unsworth, N., Redick, T. S., Heitz, R. P., Broadway, J. M., and Engle, R. W. (2009). Complex WM span tasks and higher-order cognition: a latent-variable analysis of the relationship between processing and storage. Memory 17, 635-654. doi: 10.1080/09658210902998047

Van Dyke, J. (2007). Interference effects from grammatically unavailable constituents during sentence processing. J. Exp. Psychol. Learn. Mem. Cogn. 33, 407-430. doi: 10.1037/0278-7393.33.2.407

Van Dyke, J., and Johns, C. L. (2012). Memory interference as a determinant of language comprehension. Lang. Linguist. Compass 6, 193-211. doi: $10.1002 / \operatorname{lnc} 3.330$
Van Dyke, J., Johns, C. L., and Kukona, A. (2014). Low WM capacity is only spuriously related to poor reading comprehension. Cognition 131, 373-403. doi: 10.1016/j.cognition.2014.01.007

Van Dyke, J., and Lewis, R. L. (2003). Distinguishing effects of structure and decay on attachment and repair: a cue-based parsing account of recovery from misanalyzed ambiguities. J. Mem. Lang. 49, 285-316. doi: 10.1016/S0749-596X(03)00081-0

Van Dyke, J., and McElree, B. (2006). Retrieval interference in sentence comprehension. J. Mem. Lang. 55, 157-166. doi: 10.1016/j.jml.2006.03.007

Van Dyke, J., and McElree, B. (2011). Cue-dependent interference in comprehension. J. Mem. Lang. 65, 247-263. doi: 10.1016/j.jml.2011. 05.002

Van Dyke, J., and Shankweiler, D. (2013). "From verbal efficiency theory to lexical quality: the role of memory processes in reading comprehension," in Reading: From Words to Multiple Texts, eds M. A. Britt, S. R. Goldman, and J.-F, Rouet (New York, NY: Routledge; Taylor and Francis Group), 115-131.

Verhaeghen, P., and De Meersman, L. (1998). Aging and the negative priming effect: a meta-analysis. Psychol. Aging 13, 435-444. doi: 10.1037/0882-7974.13.3.435

Vuong, L. C., and Martin, R. C. (2014). Domain-specific executive control and the revision of misinterpretations in sentence comprehension. Lang. Cogn. Neurosci. 29, 312-325. doi: 10.1080/01690965.2013.836231

WAIS-III (2002). WMS-III and Technical Manual. New York, NY: Psychological Corporation.

Warren, T., and Gibson, E. (2002). The influence of referential processing on sentence complexity. Cognition 85, 79-112. doi: 10.1016/S0010-0277(02)00087-2

Waters, G., Caplan, D., and Hildebrandt, N. (1991). On the structure of verbal STM and its functional role in sentence comprehension: evidence from neuropsychology. Cogn. Neuropsychol. 8, 81-126. doi: 10.1080/02643299108253368

Wechsler, D. (1994/1999). WASI: Wechsler Abbreviated Scale of Intelligence. San Antonio, TX: The Psychological Corporation.

Wechsler, D. (1997). Wechsler Adult Intelligence Scale, 3rd Edn: Administration and Scoring Manual. San Antonio, TX: Psychological Corporation.

Whitney, C., Kirk, M., O'Sullivan, J., Lambon Ralph, M. A., and Jefferies, E. (2011). The neural organization of semantic control: TMS evidence for a distributed network in left inferior frontal and posterior middle temporal gyrus. Cereb. Cortex 21, 1066-1107. doi: 10.1093/cercor/bhq180

Conflict of Interest Statement: The authors declare that the research was conducted in the absence of any commercial or financial relationships that could be construed as a potential conflict of interest.

The reviewer $\mathrm{CH}$ and the handling Editor declared their shared affiliation, and the handling Editor states that the process nevertheless met the standards of a fair and objective review.

Copyright (c) 2017 Tan, Martin and Van Dyke. This is an open-access article distributed under the terms of the Creative Commons Attribution License (CC BY). The use, distribution or reproduction in other forums is permitted, provided the original author(s) or licensor are credited and that the original publication in this journal is cited, in accordance with accepted academic practice. No use, distribution or reproduction is permitted which does not comply with these terms. 